\title{
Las cerámicas griegas áticas de figuras rojas de Zacatín (Granada, España)
}

\section{The Attic red figure vases at Zacatín (Granada, Spain)}

\author{
Pierre Rouillard ${ }^{1}$ \\ CNRS Francia \\ Inmaculada de la Torre Castellano ${ }^{2}$ \\ Amparo Sánchez Moreno ${ }^{3}$ \\ Universidad de Granada
}

\section{RESUMEN}

A los pies del oppidum ibérico de Iliberri en la ciudad de Granada, una excavación de urgencia en la calle Zacatín ha permitido desvelar una fosa, en cuyo interior fueron exhumados entre diversos objetos, 5000 fragmentos de cerámica (mayoritariamente griega, aunque también ibérica), así como recipientes de vidrio de origen griego. No obstante, su contexto preciso y su función están todavía por determinar. El material cerámico griego está compuesto por vasos áticos (2000 fragmentos) y presenta un carácter formal et iconográfico muy homogéneo. Nos encontramos mayoritariamente frente a copas de pie bajo, escasas copas con pie alto (forma poco abundante en la península Ibérica a la excepción de Ampurias) y de escifoi. Este conjunto podría ser datado hacia el segundo cuarto del siglo IV a. C., siendo principalmente atribuible al pintor de Viena 116 , así como ciertas piezas al Grupo FB o al pintor de Meleagro. De naturaleza excepcional, por su volumen y homogeneidad, este hallazgo permite y permitirá ahondar en las cuestiones de estructuración y de organización de los talleres de cerámica de Atenas, así como sobre las modalidades de su transporte.

\section{SUMMARY}

In the city of Granada (Spain), during a rescue excavation at the foot of the Iberian oppidum of Iliberri, calle Zacatín, 5000 pottery sherds were uncovered in a pit (mainly Greek fragments but Iberian too), and also small items of Greek glassware. The precise context and function are still obscure. Greek pottery is composed of Attic vessels (2000 fragments) having homogeneous formal and iconographic features, stemless cups especially, some cups (scarcely found in the Iberian Peninsula outside Ampurias), and skyphoi, dated to the second quarter of the 4th century BC, and which can be assigned to the Vienna 116 Painter; some other pieces belong to the Group FB et to the Meleager Painter. This exceptional set — by its homogeneity

${ }^{1}$ pierre.rouillard@mae.u-paris10.fr / ORCID iD: http://orcid. org/0000-0002-4472-1112

2 macutorre@yahoo.es / ORCID iD: http://orcid.org/00000002-0037-6134

3 amperia21@yahoo.es / ORCID iD: http://orcid.org/00000001-6267-4615 and the amount of sherds - will allow to examine in depth the questions of the Athenian pottery workshops structuring and organisation, and also of transport modalities.

PALABRAS CLAVE: Iliberri; cerámica griega; cerámica ática de figuras rojas; copas de pie alto; copas de pie bajo; taller cerámico; taller de pintor.

KEY WORDS: Iliberri; Greek pottery; red figured Attic pottery; cups; stemless cups; pottery workshop; painter workshop.

CÓMO CITAR ESTE ARTÍCULO / CITATION: Rouillard, P., De la Torre Castellano, I. y Sánchez Moreno, A. 2017: "Las cerámicas griegas áticas de figuras rojas de Zacatín (Granada, España)". Archivo Español de Arqueología, 90: 271-298. doi: 10.3989/aespa.090.017.012

\section{EL YACIMIENTO DE ZACATÍN Y EL OPPIDUM DE ILTURIR/ILIBERRI (GRANADA)}

El oppidum de Ilturir/Iliberri sólo recientemente ha sido objeto de estudios que permitan conocer la entidad de su trama urbana así como de los componentes sociales, religiosos, territoriales, paisajísticos o económicos de lo que supuso el origen y desarrollo de un núcleo urbano que, como otros coetáneos y vecinos, surgió como consecuencia de un proceso de sinecismo que agrupó a diversas poblaciones creando en el actual barrio granadino de El Albaicín uno de los asentamientos ibéricos más importantes del sureste peninsular y Alta Andalucía (Fig. 1), pero uno de los peor conocidos, a pesar de que ya en los años 60 del pasado siglo xx era objeto de un estudio sistemático una de sus necrópolis (Arribas 1967). Y es que una serie de circunstancias poco acertadas ralentizarían el conocimiento arqueológico de este yacimiento multifásico. 


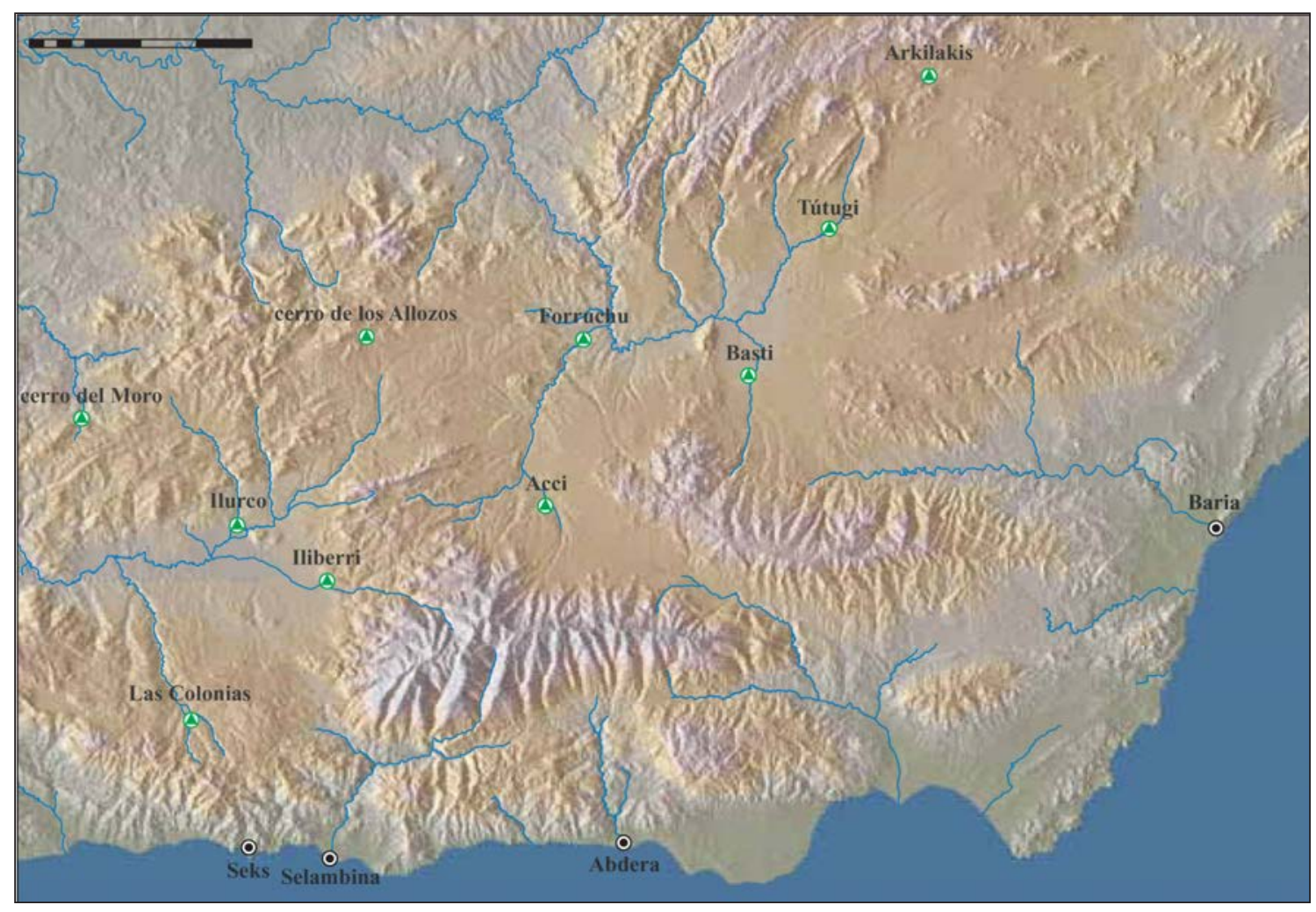

Figura 1. Los oppida ibéricos.de Alta Andalucia (Fuente: Adroher 2008: fig.1).

Por un lado, la propia historia de la arqueología de la ciudad, iniciada a mitad del siglo XvIII de la mano de un curioso personaje, Juan de Flores, quien falsificó con nocturnidad y alevosía el registro arqueológico para intentar confirmar la existencia en el suelo granadino de una ciudad romana que estuviese a la altura de la que, según las fuentes clásicas, había sido sede de uno de los primeros concilios de la cristiandad a principios del siglo IV d. C., el de Elvira.

Por otro, la existencia de una ciudad homónima muy cercana, de la que se conocían bien sus restos medievales, Medina Elvira, situada a unos $15 \mathrm{~km}$ al Oeste de la actual ciudad de Granada, y que polarizó gran parte de los estudios historiográficos hasta el punto de que, según algunos autores (Mora 1998), el debate en torno a la ubicación de la ciudad romana y la medieval en el Albaicín o en Sierra Elvira fue uno de los que más enfrentamientos produjo en la historiografía española del siglo XIX.

Las excavaciones sistemáticas y de urgencia que empezaron a desarrollarse en la ciudad de Granada a partir de 1982 ayudaron a definir el diseño de las diversas tramas urbanas en las distintas fases de ocupación, aunque más profundamente en los períodos romano y medieval que en la ibérica.
Ello ha permitido que diversos estudios recientes hayan aportado una gran cantidad de información sobre la ciudad romana (Orfila 2011, con amplia bibliografía), en detrimento de lo que conocemos sobre la fase protohistórica, lo que ha sido resaltado en la historiografía reciente, señalando la escasez de datos con que se cuenta en la actualidad y el problema que ello provoca a la hora de entender un espacio ligado a la Bastetania ibérica, a pesar de las críticas acerca de este concepto cultural que empezaron a surgir en este momento (Adroher 2008).

Todas las publicaciones siguientes no hacían sino resaltar la necesidad de enfrentar un estudio de conjunto que finalmente ha tenido lugar en una tesis doctoral defendida por una de nosotras (Sánchez Moreno 2016).

$\mathrm{Y}$ el caso es que algunos artículos especializados publicados en estos dos últimos decenios habían profundizado en las fases prerromanas, pero sin a analizar con detenimiento la cantidad de datos que han visto la luz gracias a este estudio de conjunto.

Tras la defensa de este trabajo de investigación las ideas se han aclarado bastante, y surgen nuevas proyecciones de investigación que permitirán en breve avanzar notablemente en el conocimiento del oppidum 
de Iliberri tanto en su distribución urbana como en sus contextos social, económico, religioso y paisajístico.

Por su parte, los trabajos precedentes ya habían resaltado la importancia de ciertos hallazgos, y la tesis defendida hace un exigente hincapié sobre el alto valor de algunos de estos hallazgos, contextualizándolos tanto en el espacio como en el tiempo. Así ya podemos proponer que apenas un siglo después de la fundación del oppidum hacia el 675 a. C. (Adroher y López 2001), se proyectó una gran reforma urbana que supuso la creación de nuevos lienzos de muralla que crearan un espacio intramuros que duplicaba el de la fase fundacional. Iliberri (quizás con el nombre de Ilturir) debió sufrir la crisis del siglo vi a. C., tras lo cual el único argumento que tenemos desde la arqueografía para conocer su continuidad es la existencia de varias necrópolis (Mirador de Rolando y Mauror), la presencia de material ático en algunos sedimentos, el depósito que centra este trabajo (calle Zacatín) y poco más. Es posible que hayan tenido lugar reformas urbanas importantes de las que apenas vemos la punta del iceberg, quizás en la construcción del depósito de agua de la calle Álamo del Marqués (Lozano et alii 2008), el cual se amortizó un par de siglos más tarde, presumiblemente.

En la fase tardoibérica la ciudad emite moneda, cuatro series que siguen planteando problemas de clasificación, pero que denotan la importancia social y económica de este núcleo urbano. Algunos elementos repartidos en diversos hallazgos nos permiten considerar que Iliberri se sitúa como centro de consumo y redistribuidor de un comercio con marcado carácter mediterráneo, lo que hace que encontremos todo tipo de producciones cerámicas, barnices negros campanos y etruscos, boles griegos, ánforas itálicas, adriáticas, del bajo Guadalquivir, de la bahía de Cádiz y Málaga; importaciones de kalathos y de jarritas monoansadas de gris de la costa catalana permiten igualmente identificar una potente fuente de interrelación con las costas levantinas peninsulares.

Entre todos los hallazgos que se asocian a época ibérica en el casco antiguo de la actual ciudad de Granada, sin lugar a dudas uno de los más interesantes es el que centra el presente trabajo, del depósito votivo ibérico junto al rio Darro, en la calle Zacatín (Fig.2).

Dicho contexto fue localizado en 1999, y fue inicialmente interpretado como restos de un depósito de carácter funerario (Pachón 1997-1999; Rambla y Cisneros 2000; Rambla y Salado 2002), y así fue considerado hasta que un equipo en el cual estábamos integradas dos de las autoras de este trabajo, encaró desde el año 2004, un proyecto de análisis pormenorizado de los documentos arqueográficos recuperados en la excavación, fruto de lo cual se han llevado a cabo diversas publicaciones que insisten en su carácter votivo, pero al margen del ámbito funerario (De la Torre 2008; Rouillard y De la Torre 2014; Adroher et alii 2015; Sánchez Moreno et alii 2015).

El conjunto mueble recuperado se compone de unos 5.000 fragmentos de cerámica (griegas especialmente, pero también ibéricas comunes, ibéricas de barniz rojo y algunos fragmentos aislados púnicos), repartidos en casi $40 \mathrm{~kg}$, a lo que se unen otros materiales de otra naturaleza como elementos metálicos (destacando un trípode), hueso trabajado (una placa decorada inspirada en motivos orientalizantes), restos de huevo de avestruz, arcilla cocida (sobre todo fusayolas) y elementos de pasta vítrea de los que destaca un nutrido grupo de ungüentarios que han sido ya presentados en un trabajo específico (Vílchez et alii 2005).

Estructuralmente se trata de una fosa poco profunda excavada junto a los arenales de depósito del río Darro, al exterior de la muralla del oppidum y por el momento sin ninguna asociación de rituales que indiquen su pertenencia al ámbito funerario. No hay datos para saber si se integraba dentro de algún complejo estructural de mayores dimensiones, ya que la excavación se centraba en un pequeño solar que no permitía la apertura en open area, lo que imposibilitó que los excavadores pudieran tener la posibilidad de contextualizar adecuadamente el hallazgo (Rambla y Salado 2002).

La gran cantidad de material ático permite identificar cronológicamente este depósito en una fase coetánea a la datación del pecio de El Sec, dentro del segundo cuarto del siglo IV a. C., aunque aún se podría precisar algo más esta propuesta; aunque en este trabajo se presentan solamente las cerámicas griegas de figuras rojas, las de barniz negro también han sido objeto de un estudio monográfico y cuya composición tipológica y porcentual también parece apuntar en la misma línea (Adroher et alii 2016).

El material, en líneas generales, está muy rodado, especialmente los vasos áticos figurados, lo que nos permite considerar que pudieron haber sido arrojados a la fosa una vez rotos o con el suficiente ímpetu como para que fracturaran en pequeños fragmentos al caer con tanta fuerza contra el suelo. Por su parte, el agua del río ha provocado un proceso de erosión tal que evita, en numerosas ocasiones, que los fragmentos puedan ser reconocidos $\mathrm{y}$, en consecuencia, puedan clasificarse adecuadamente.

El fuego parece que también debió jugar un importante papel en el ritual, ya que muchas piezas presentan restos de estrés térmico incluso en las zonas de fractura, lo que indica que se quemaron tras su fragmentación (Adroher et alii 2015). 


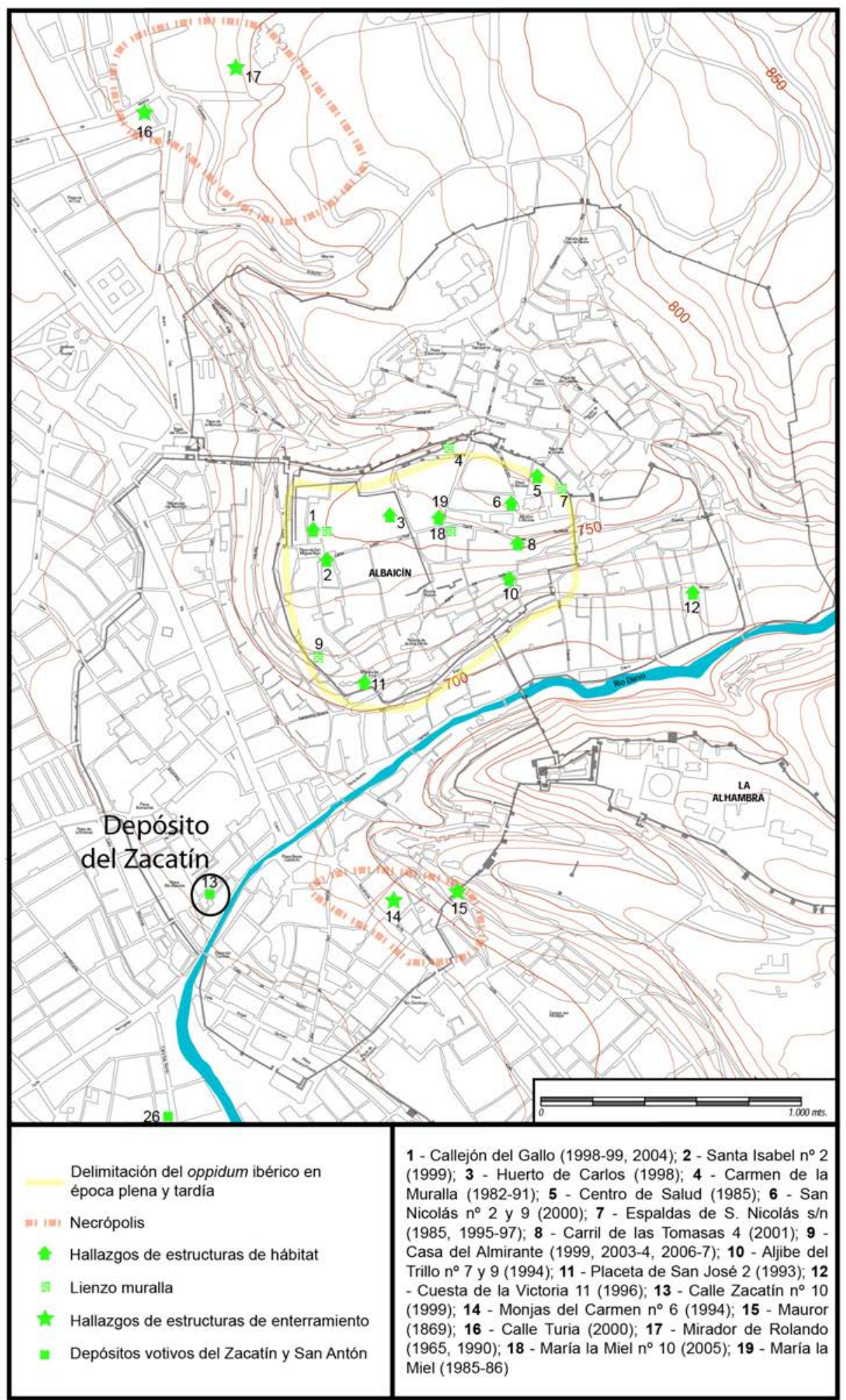

Figura 2. Ubicación de Iliberri y el depósito de Zacatín (Fuente: Adroher et alii 2016: fig. 1). 


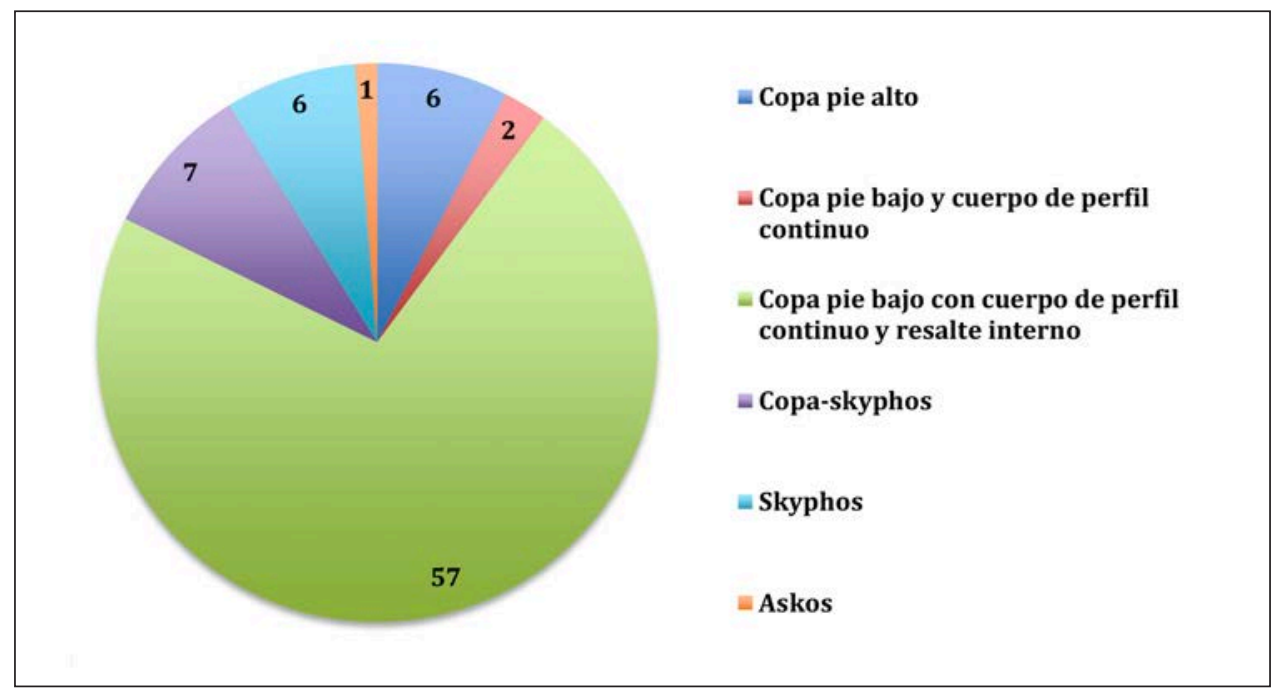

Figura 3. Gráfico de número de vasos según tipología.

\section{LAS CERÁMICAS ÁTICAS DE FIGURAS ROJAS}

A partir de 2.000 fragmentos de cerámica ática de figuras rojas de pequeño tamaño excavados en parte de una fosa (Rambla y Salado 2002) donde se habrían arrojado cientos de vasos el tratamiento y estudio de todo este material ático de figuras rojas nos ha permitido presentar 79 individuos bien identificados ${ }^{4}$. Por supuesto hay muchos fragmentos que quedan aislados, sin poderse remontar, ya que parte de la fosa (la mitad o más) no fue objeto de excavación al quedar fuera del solar afectado por la intervención arqueológica.

Una característica importante de este conjunto es la homogeneidad del repertorio de formas y la cronología de las piezas, con alguna ligera diferencia en el último caso. Las formas consisten casi exclusivamente en vasos del servicio de bebida, copas de pie alto y copas de pie bajo, copas-escifoi o escifoi y un solo vaso cerrado (Fig. 3).

La gran mayoría de las piezas puede ser datada en el segundo cuarto del siglo IV a. C., aunque contamos con dos copas de pie bajo (049 y 060) del último tercio del siglo $\mathrm{v}$ a. C., periodo al cual pertenecen dos piezas de barniz negro, una "Copa Cástulo" (Rambla y Salado 2002: fig. 4, 10; Adroher et alii 2016: fig. 3, 2-3), un "bolsal" (Rambla y Salado 2002: fig. 5, 12), con un escifo de tipo "Saint Valentín" y copas de pie alto de principios del siglo IV a. C.

La ausencia de orificios de reparación y de cualquier restauración es otra característica común de

\footnotetext{
${ }^{4}$ Tomamos para citar cada individuo el número de la base de datos SIRA (Adroher 2014 a y b).
}

estos vasos, un argumento que refuerza la hipótesis de que se trata de un depósito compuesto por piezas que no fueron utilizadas, o que fueron poco utilizadas, lo que ocurriría seguramente con las piezas más antiguas; todas las piezas del segundo cuarto del siglo IV a. C. debieron ser adquiridas en un corto espacio de tiempo (en vista de la homogeneidad de los vasos), y se usaron para un acto preciso realizado en un momento dado, por lo que el depósito de Zacatín es un excepcional conjunto cerrado.

\subsection{Copas De pie alto: 042, 055, 056, 057, 058,} 083 (FIG. 4)

De seis copas de pie alto, cinco presentan características parecidas, tanto formales como por el estilo y la iconografía ${ }^{5}$, y una última copa (083) es objeto de debate. Se trata de copas del tipo "B" de Bloesch (Bloesch 1940). Ornamentación bajo las asas: una palmeta vertical, rodeada en la base a un lado y otro de volutas que sostienen pequeñas palmetas rodeadas de follaje $(056,057,058)$, o de pequeñas palmetas $(042,083)$ o de volutas $(055)$.

${ }^{5}$ Cuatro de estas copas $(055,056,057,058)$ ya han sido publicadas por nosotros mismos en la Revista de Estudios de Arqueología Bastetana, 2, 1, 2014, p. 1-14. Uno de nosotros (P. R.) propuso su atribución a un taller del segundo cuarto del siglo IV y la señora Kleopatra Kathariou tuvo la amabilidad de discutir estos análisis, proponiendo de manera más categórica su atribución al Pintor de Meleagro al que ya hizo referencia el ponente. Le damos las gracias y en este análisis seguimos esta reflexión en la estructuración de los talleres de este periodo. 


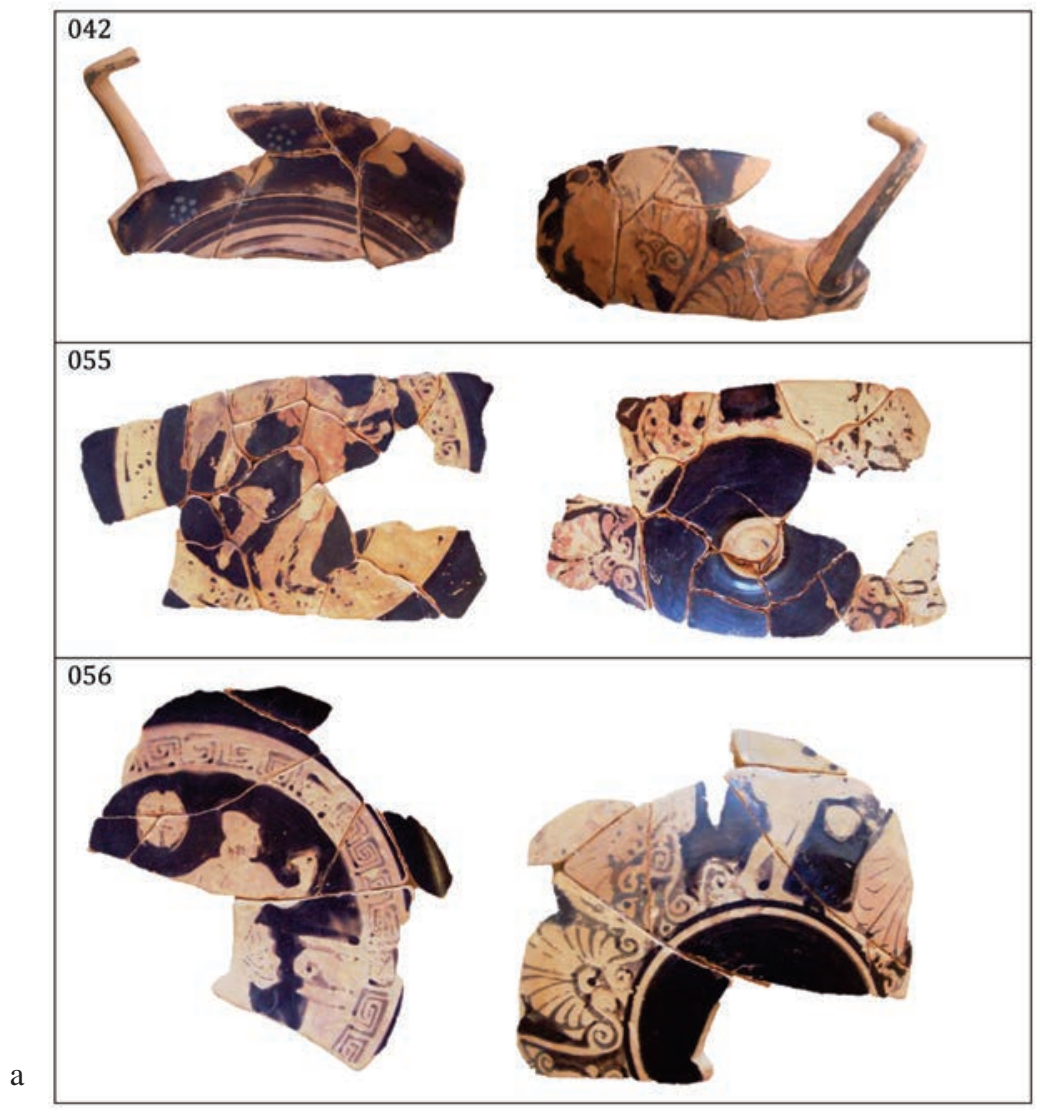

Figura 4. a: Copas de pie alto.

De la copa 042 (Fig. 4a) queda legible un fragmento de borde decorado en el interior del labio por rosetas de puntos. La ornamentación bajo las asas está constituida por una palmeta enmarcada por dos pequeñas palmetas. A: dos personajes enfrentados; a la derecha, lo único visible es una mujer con un moño (similar a Londres BM, 21 E, Curti 2001: n. 133). Diámetro del vaso: $17 \mathrm{~cm}$.

El fragmento de 055 (Fig. 4a) es una parte del fondo del vaso. Medallón rodeado por una greca. Eros desnudo de perfil hacia la derecha, sosteniendo en cada mano un objeto de difícil identificación (¿fíala en la mano izquierda? ¿aribalo en su mano derecha?). A la izquierda, ritón. Exterior A: probablemente dos personajes cara a cara. A la izquierda, dos piernas desnudas de perfil hacia la derecha; a la izquierda, parte inferior de un himatión (¿?). Longitud máxima conservada: $16 \mathrm{~cm}$.

El fragmento de 056 (Fig. 4a) es una parte del fondo del vaso. Medallón rodeado por una greca interrumpida por rectángulos reservados, con cruz punteada. Lagunas a la izquierda y abajo. Joven de frente con el torso desnudo, (¿de pie o sentado?), cabeza de perfil hacia la derecha, el brazo izquierdo levantado sosteniendo probablemente un ritón. Ropa anudada a la altura de la cintura. Lleva un gorro (¿un pilos?), del que se escapan, cubriendo la nuca, mechones de pelo rizado. El brazo se dobla por encima de una pilastra coronada por una voluta. En el campo, a la izquierda de la cabeza, dos halteras contiguas. En el exterior, se observa, en la cara A, la parte inferior de dos personajes enfrentados: a la izquierda, probablemente Eros, del que se ve a la izquierda el extremo inferior del ala, y enfrente a un personaje en himatión. Longitud máxima conservada: $15 \mathrm{~cm}$.

El fragmento de 057 (Fig. 4b) es parte del fondo de la copa. Medallón rodeado por una greca interrumpida por rectángulos reservados, con cruz punteada. Eros desnudo de perfil hacia la derecha. Sostiene en su mano derecha un estrigilo encima de un luterio. Cabello corto rodeado de un filete reservado. Exterior A: Eros frente a joven con himatión. Longitud máxima conservada: $18 \mathrm{~cm}$.

El fragmento de 058 (Fig. 4b) conserva el pie y una parte del fondo del vaso. Medallón rodeado por una greca interrumpida por rectángulos reservados 


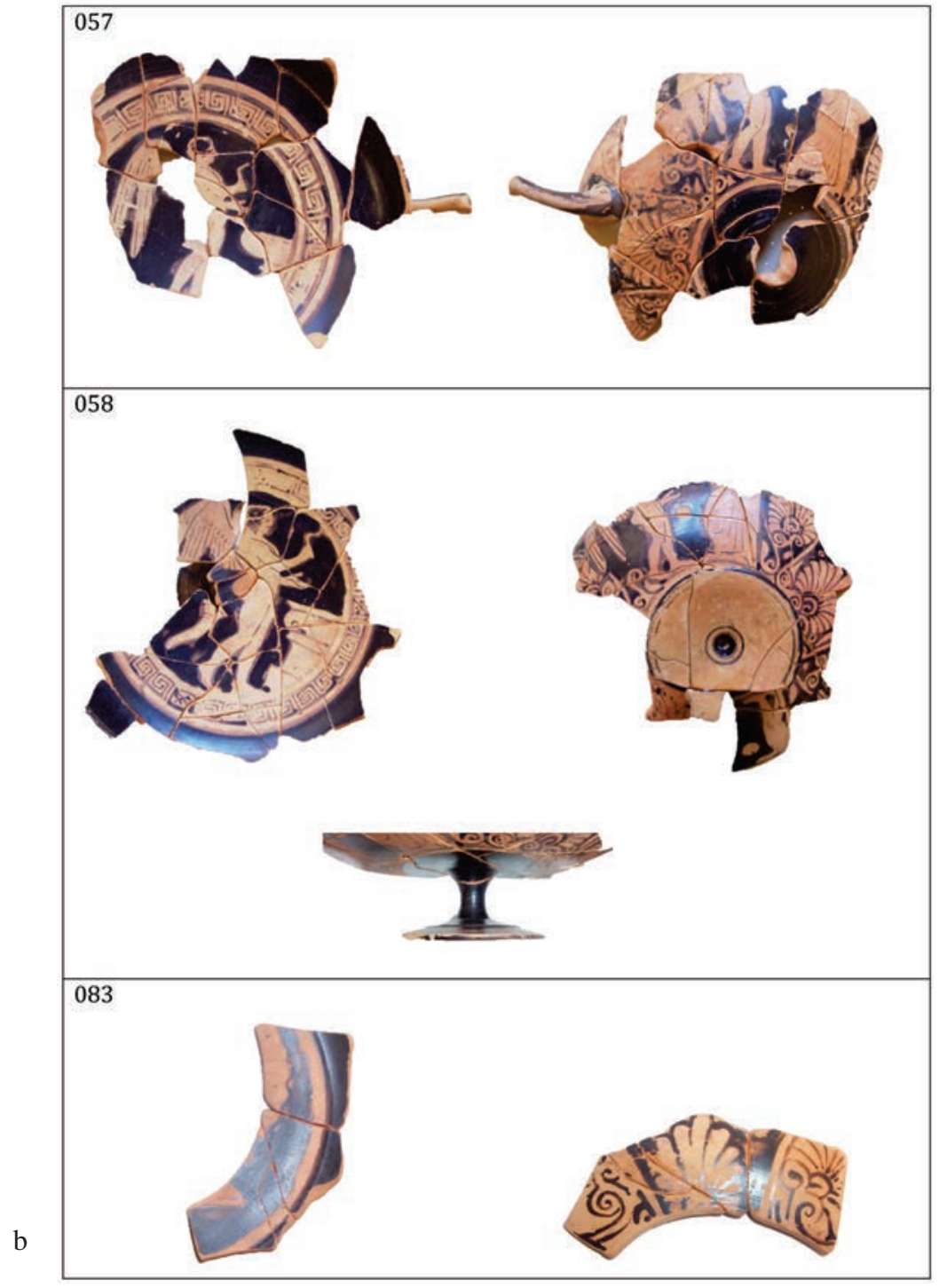

Figura 4. b: Copas de pie alto.

con cruz punteada. Eros desnudo de perfil mirando hacia la derecha; alas desplegadas. Cabello con rizos caídos rodeado por un filete reservado. Sostiene en su mano derecha un estrigilo encima de un altar con volutas. A la izquierda, ritón. A: Eros (¿sosteniendo un aribalo?) frente a un personaje en himatión. B: probablemente idéntica escena; solo se conserva Eros dirigiéndose hacia la derecha. Longitud máxima del vaso conservada: $15,5 \mathrm{~cm}$; diámetro de pie: 7,7 cm; altura pie: $4,1 \mathrm{~cm}$.

El fragmento 083 (Fig. 4b) es parte del fondo de una copa. El medallón (diámetro: $13 \mathrm{~cm}$ ) está rodeado por un círculo reservado. Se reconoce una base o un pie mirando hacia la derecha $(i$ ?); por encima, siguiendo la curvatura del medallón, una línea ondulada. Se podría avanzar la hipótesis de una concha de donde surgiría Afrodita como en la pélice de Olinto (Tesalónica, Museo Arqueológico, 685; BA 14847: LIMC II, s. v. Aphrodite, $\mathrm{n}^{\circ} 1183$; Kossatz-Deissmann 1986; Trakatelli 2011), pero el espacio parece demasiado restringido para tal escena. La línea ondulada podría ser también la cola de un tritón. La cuestión sigue abierta. Longitud máxima conservada: $10,4 \mathrm{~cm}$.

Estas copas constituyen un lote que presenta la misma forma de copa, la elección de una iconografía bien definida, una organización y una composición de la decoración muy parecidas, incluso idénticas, 
un sistema decorativo que se repite y una manera de pintar muy similar. Se observan una serie de constantes en la iconografía. Así, en el medallón, un solo personaje cubre el centro del espacio, y siempre a la derecha, un altar. En el exterior, de manera repetitiva, dos personajes de pie uno frente al otro. Los medallones presentan una iconografía que ofrece una cierta variedad solamente en los accesorios y atributos; en tres casos sobre cuatro se trata de Eros, que en dos ocasiones tiene un estrigilo (057 y 058), lo que es raro y constituye una característica propia de este lote ${ }^{6}$; en el caso de la copa 056 , estamos siempre en un ambiente de palestra con halteras en el campo. Un cuerno de beber se encuentra en los medallones de las copas 055 y 058 . El altar se refiere a la ofrenda, los personajes, Eros o jóvenes, al mundo de la palestra; más allá de algunos casos en los que Eros que sostiene un estrigilo, las escenas que asocian Eros y atletas están bien documentadas en el Pintor de Meleagro ${ }^{7}$. Los accesorios y atributos, fíala, halteras, estrigilo, cuerno para beber están reunidos y asociados en una variada mezcla de universos que son los de la ciudad griega, los banquetes, la palestra y Eros. La atribución al taller del Pintor de Meleagro, ya sugerida por la iconografía, se basa también en el estilo: así los Eros que se encuentran en las copas de Zacatín son tratados, por ejemplo, de la misma manera que en la copa de Eretria 1530 (Kathariou 2002: MEL 106, pl. 37B) o en la crátera de Würzburg H 4643 (Kathariou 2002: MEL 28, pl. 13B), o de nuevo la mujer que lleva un moño de la copa 042 es cercana a la de la copa de Londres, BM E121 (Curti 2001: n. 133). Todas estas filiaciones, si uno sigue Kathariou y Curti, convergen para proponer una fecha en el momento final de producción del taller, a principios del siglo IV a. C. ${ }^{8}$

\subsection{Copas De PIE BAJO y CUERPo DE CURVATURA CONTINUA: 049, 060. (FIG. 5)}

Dos copas de pie bajo se distinguen por su cuerpo con perfil de curvatura continua, su pie ligeramente oblicuo, convexo (049) o biconvexo (060), sin mol-

\footnotetext{
${ }^{6}$ Vemos algunos casos de Eros sosteniendo un estrigilo; así en el Pintor de Meleagro: BA 17837 (Museo de Eretria 1530, Kathariou 2002: MEL 106, pl 37 una copa de pie alto, datada en el "período tardío" por Kathariou); y la hidria BA 11847 ("late IV") del Museo Británico, E239 (CVA, Br. M., VI, p. 99, 2).

${ }^{7}$ De estas asociaciones varias se encuentran sobre cráteras: nos remitimos a Curti 2001, n. 17B, 31B, 32B, 47B, 57 y Kathariou 2002, n. 132 (en este caso una copa de pie bajo).

${ }^{8}$ Así Curti 2001: 41 (la pieza n. 133 está situada en la "fase reciente") y Kathariou sitúa en el "período tardío" el vaso MEL 106 (ver supra, nota 3).
}

duras y una pared gruesa $(4.5 \mathrm{~mm})$. Esta forma se identifica como copa "plain rim" en la serie de vasos de barniz negro del Ágora de Atenas (Agora XII, $\mathrm{n}^{\text {os }}$ 474 - 482) y se data entre 450 y 425 a. C.

La copa 049 presenta un perfil completo con asa incluida. Medallón rodeado por una greca continua; cabeza masculina de perfil con petaso hacia la derecha; cabello caído sobre la sien. Exterior barnizado en negro. Altura: $4,8 \mathrm{~cm}$, diámetro de boca: $15 \mathrm{~cm}$, diámetro de base: $8 \mathrm{~cm}$.

La copa 060 también presenta un perfil completo, aunque no conserva las asas. Medallón rodeado por una banda continua de "z" (zetas); palmeta con pétalos alargados desplegados. Exterior: barniz negro con el interior del pie con rojo intencional. Altura: $3,9 \mathrm{~cm}$, diám. boca estimado: $13-14 \mathrm{~cm}$; diam. pie estimado: 7,5-8 cm (Cf: para la palmeta: Beazley 1948: 4647, fig. 2-3 y lám. XV y Trías 1967: 403, n. 8, lám. CLXXX,15, de Cabezo del Tío Pío, Archena, Murcia; para la banda de "z": Beazley 1948: 45, fig. 2-4, lám. XVI; Trías 1968: 403, n. 6 y 7, lám. CLXXX, 12 y 13 del mismo sitio; Miró 2006: catálogo p. 140, lám. 63-n. 608, de Ampurias, Girona; Wiel -Marin 2005, n. $1134=$ BA 13213).

Estas dos piezas son excepcionales por su iconografía, muy inusual en este tipo de copas. El mismo tipo de copa, con curvatura continua, se encuentra en la necrópolis del Mirador de Rolando (Granada) (Trías 1967-1968: p. 454, pl. CCI, 10).

\subsection{Copas de PIE BAJO CON CUERPo DE CURVATURA CONTINUA Y RESALTE INTERNO (FIG. 6-12)}

Las copas de pie bajo, con cuerpo de curvatura continua y con resalte interno constituyen el conjunto más importante (57 de 79 individuos) y se caracteriza por su gran homogeneidad, tanto por la forma como por el tratamiento de la ornamentación y de la iconografía, con un repertorio reducido.

La forma es similar a la que se identifica en el Ágora de Atenas con el nombre de "stemless cup, delicate class" (Agora XII: n. 474 hasta 492) y se caracteriza por un cuerpo de poco espesor, un pie moldurado que a veces reserva la superficie de apoyo ${ }^{9}$. Las dimensiones son muy similares de una pieza a otra: diámetro de cuerpo entre 14 y $16 \mathrm{~cm}$, diámetro de pie entre 7 y $8 \mathrm{~cm}$ (pero lo más frecuente 7 $\mathrm{cm}$ ) y una altura entre 4 y 4,8 cm. La decoración consiste en una palmeta bajo la zona de las asas, y en palmetas o volutas a un lado y otro de las asas;

\footnotetext{
${ }^{9}$ Ver Lattara 6 , Dicocer, AT- FR Ky 14
} 


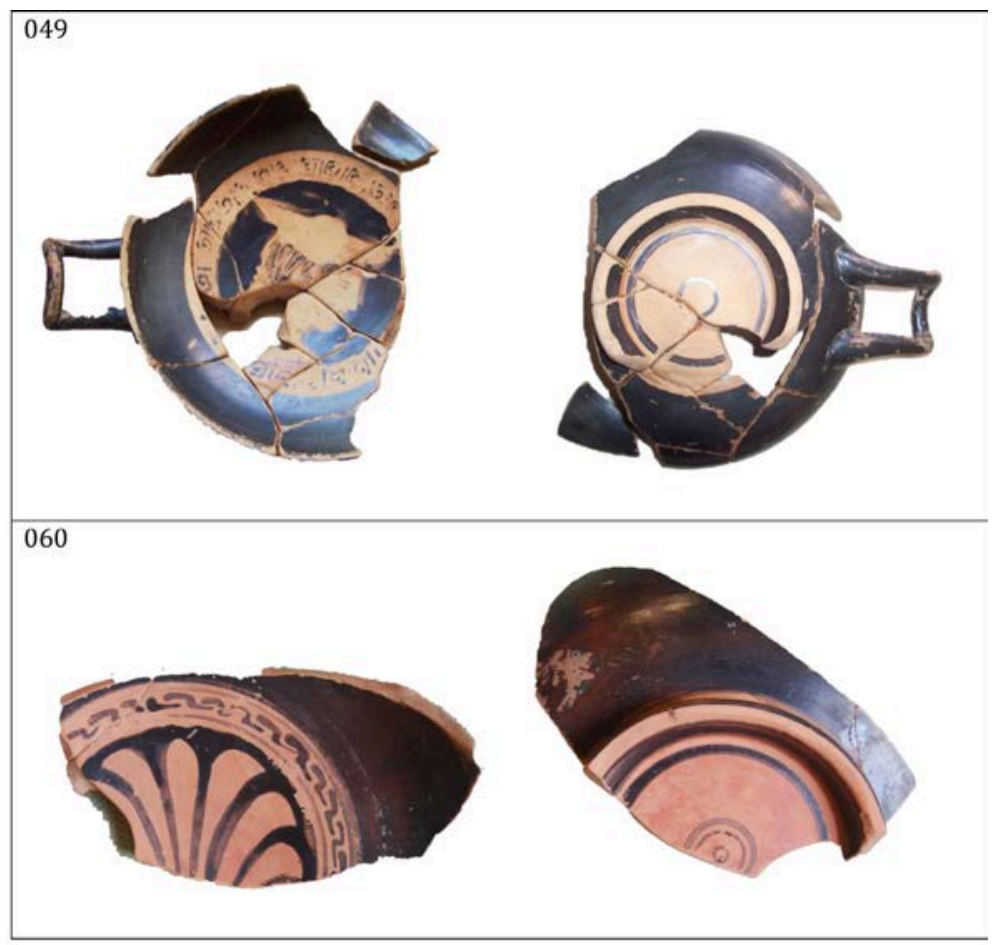

Figura 5: Copas de pie bajo y cuerpo de curvatura continua.

en el fondo externo del pie: círculos reservados. El medallón está generalmente rodeado por uno o varios círculos reservados. El labio puede tener ramas y rosetas de puntos superpuestos en pintura blanca (001, 002, 006, 014, 016, 034, 035, 038, 040, 048) o ramas de hojas de hiedra (003).

El pintor, o los pintores, de estas copas compartían el mismo gusto por la decoración llenando todo el espacio, ya se trate del medallón o de los exteriores. No se dejan espacios vacíos y pintan los atributos que sostienen los jóvenes llenando el espacio entre la escena del medallón y su mismo límite, o el espacio entre los dos personajes de los exteriores.

Los rasgos comunes de estas copas se presentan a continuación y resaltaremos solamente los rasgos distintivos de cada uno de los siete grupos definidos a partir de la iconografía del medallón.

El trazo de contorno es inexistente o, cuando existe (por ejemplo, 027, 029, 030, 035, 040), no es continuo y toma la apariencia de una rebaba. El contorno de la cabeza de los jóvenes en himatión o desnudos es impreciso, con una protuberancia hacia la derecha para representar la nariz; el volumen del cabello se realiza con una mancha negra y los mechones son raros. La boca está marcada, en todo caso, por un punto. Cuando el ojo se indica, se hace con un trazo (017), dos trazos $(005,010,015,020$,
029, 031, 039), dos trazos y un punto $(016,024$, 030, 034, 038) o un punto (023). Los dedos de las manos no se distinguen unos de otros, excepto en el caso de un dedo levantado (011, 020, 032, 040). El tratamiento de los pies varía según el joven esté desnudo o vistiendo un himatión. El sexo de los jóvenes desnudos casi no se indica.

La decoración exterior, estudiada a partir de 31 casos bien conservados, consiste en la mayoría de los ejemplos en dos jóvenes en himatión enfrentados (24 casos: 001, 002, 004, 011, 012, 014, 016, 018, 025, 026, 029, 030, 031, 032, 034, 037, 038, 043, 052, 062, 069) y, en menor proporción (7 casos: 005, 006, 007, 008, 044, 075, 084), en una cabeza femenina frente a un joven en himatión. Los unos y los otros son tratados de la misma manera que en los medallones y los atributos y accesorios (los mismos que en los medallones) llenan el espacio; así para los jóvenes en himatión: mano que sostiene una caja $(001,002)$, un bastón $(001,012,014)$, un aribalo $(002,006)$, un estrigilo (014), y el círculo de puntos (006), ova entre las cabezas $(002,016)$, equipamiento del atleta (031), disco con cruz (034). No parece que se puedan establecer conexiones privilegiadas entre la decoración del medallón y los reversos.

Más allá de estos rasgos generales, que pueden ser a veces matizados, la clasificación aquí propuesta 

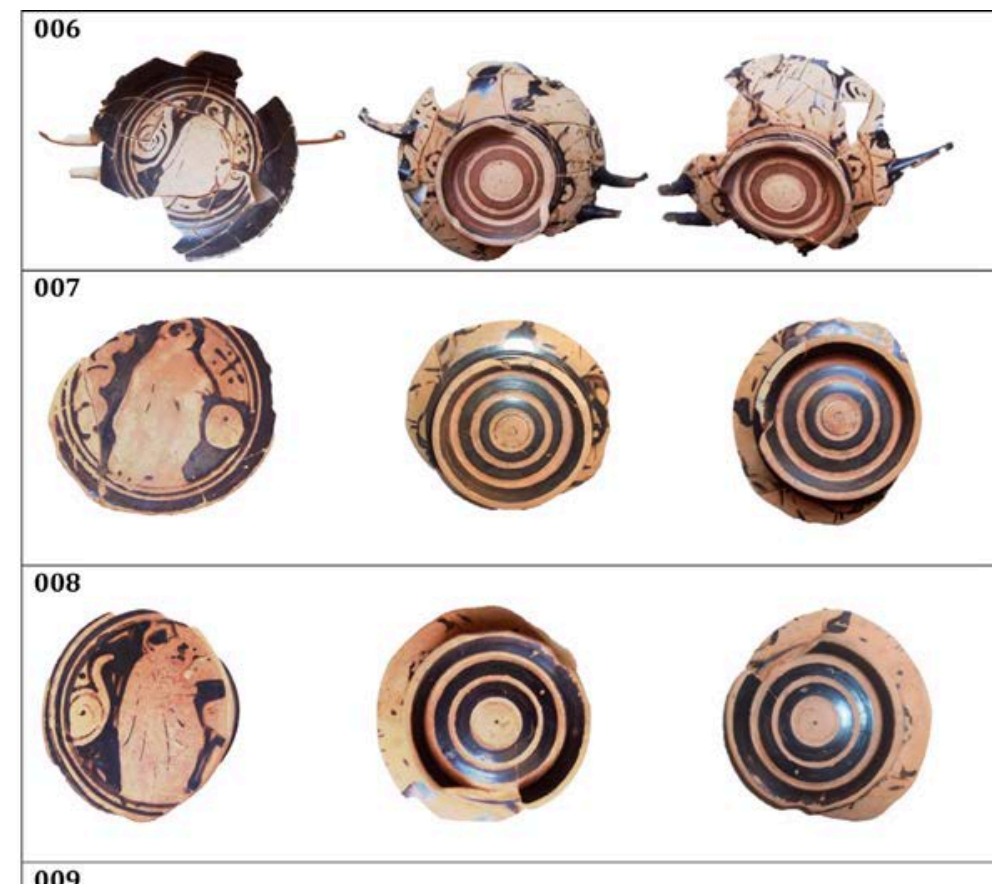

009
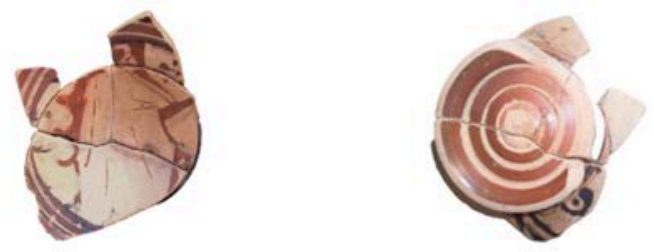

010

a

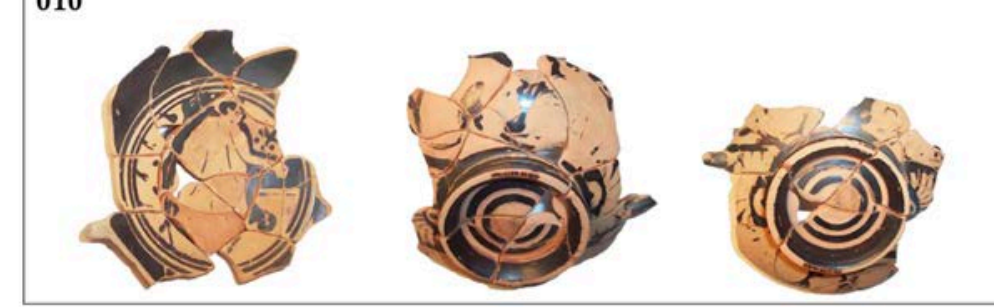

Figura 6. a: Medallones con joven vestido con himatión.

se organiza a partir de la decoración pintada en el medallón y distinguimos siete casos, tres de los cuales son particularmente frecuentes: joven en himatión, joven desnudo y cabeza femenina.

2.3.1. Joven en himatión: 006, 007, 008, 009, 010, 011, 012, 013, 014, 015, 016, 017, 018, 019, 020, 021, 023, 026 (Fig. 5a-d)

El joven de pie y de perfil mirando hacia la derecha, está vestido con un largo y ancho himatión señalado solamente con algunos trazos verticales; la anchura de la prenda es a veces tal que ocupa casi todo el espacio del medallón (013,021,041); el cuello es tratado solamente por dos muescas entre la parte superior del manto y la cabeza; el himatión cubre a menudo los pies $(008,009,010,013,014,015,020)$, pero en otros casos $(006,007,012,017,018,019$, 021, 026) los pies están esbozados por una punta hacia la derecha; la planta del pie se ajusta entonces a la curvatura del medallón. A su izquierda el espacio está cerrado sea por un risco $(007,009$, ¿010?), una media voluta $(006,008)$, a veces un pilar (011). A su derecha, un pilar $(012,014$, ¿018?, ¿020?), o un luterio (008, 009, 010, 017). Estos elementos tienen 


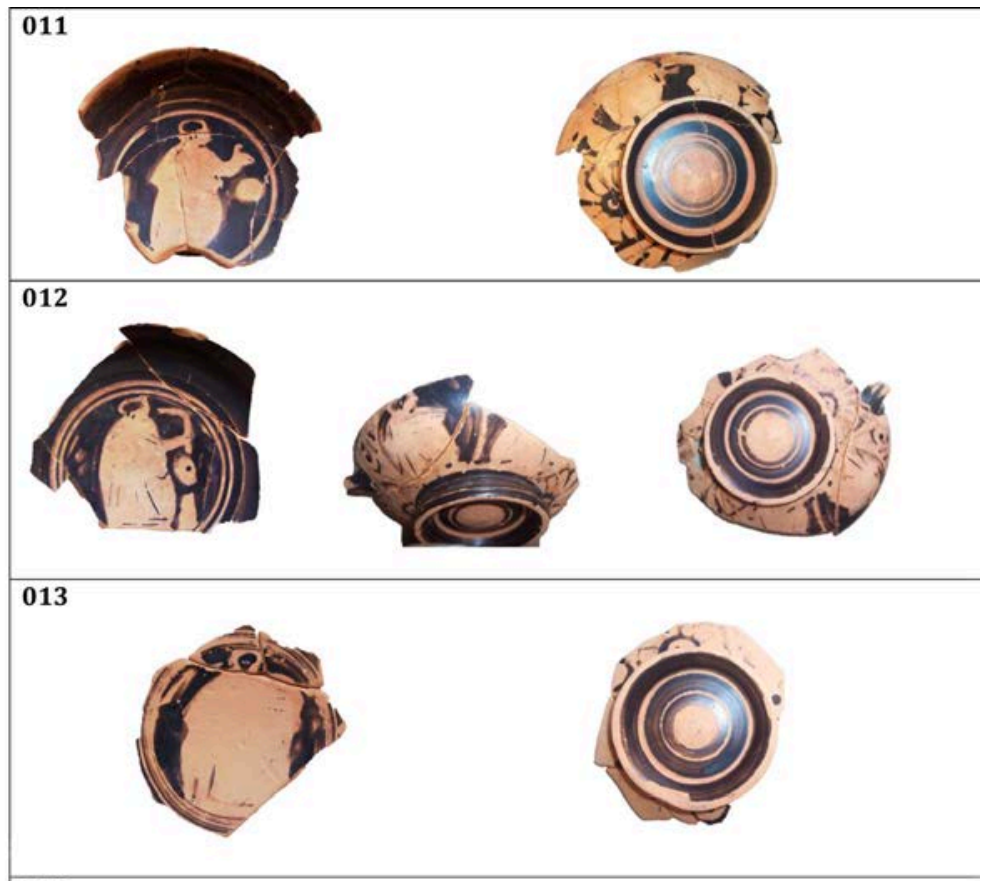

014
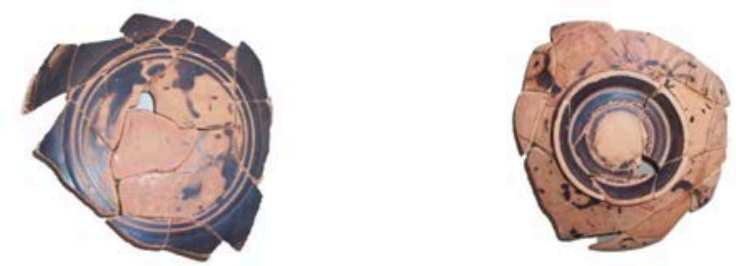

015

b
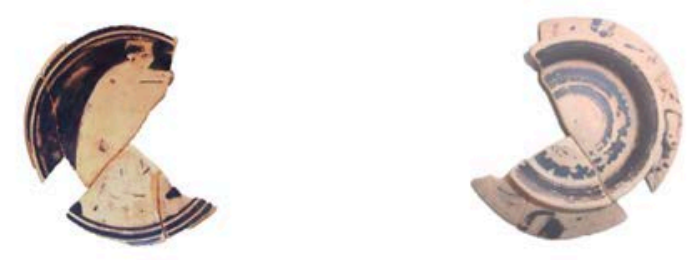

Figura 6. b: Medallones con joven vestido con himatión.

sentido cuando el joven tiende un brazo por encima de este luterio o de este pilar, colgando lo que nosotros identificamos como un aribalo, aunque el cordón necesario para sostenerlo no sea visible $(010,012)$; el aribalo también puede estar presente, pero suspendido en el vacío (007, 011, 016, 026). En un caso (012), tenemos un joven con un estrigilo y quizás también un aribalo.

En el afán de rellenar todo el espacio, el pintor sitúa frente a la cabeza un disco con un punto central (023) o un disco con una cruz y cuatro puntos inscritos (007, 009, 010, 014).
2.3.2. Joven desnudo: 005, 024, 027, 029, 030, 032, 034, 035, 036, 038, 039, 040, 063, 085 (Fig. 6e-g)

Siempre de perfil hacia la derecha, el joven desnudo siempre está solo, enmarcado por atributos y elementos accesorios. Las proporciones entre el busto y los diferentes miembros son tratados de manera somera $(030,032,034)$. Un pie sobre una piedra o un pilar $(024,027,034,039)$ o sobre la base de un luterio (030); con mayor frecuencia el joven tiende los brazos hacia adelante, por encima o de un altar $(024,31,40)$ o de un luterio $(005,029,030,032$, 


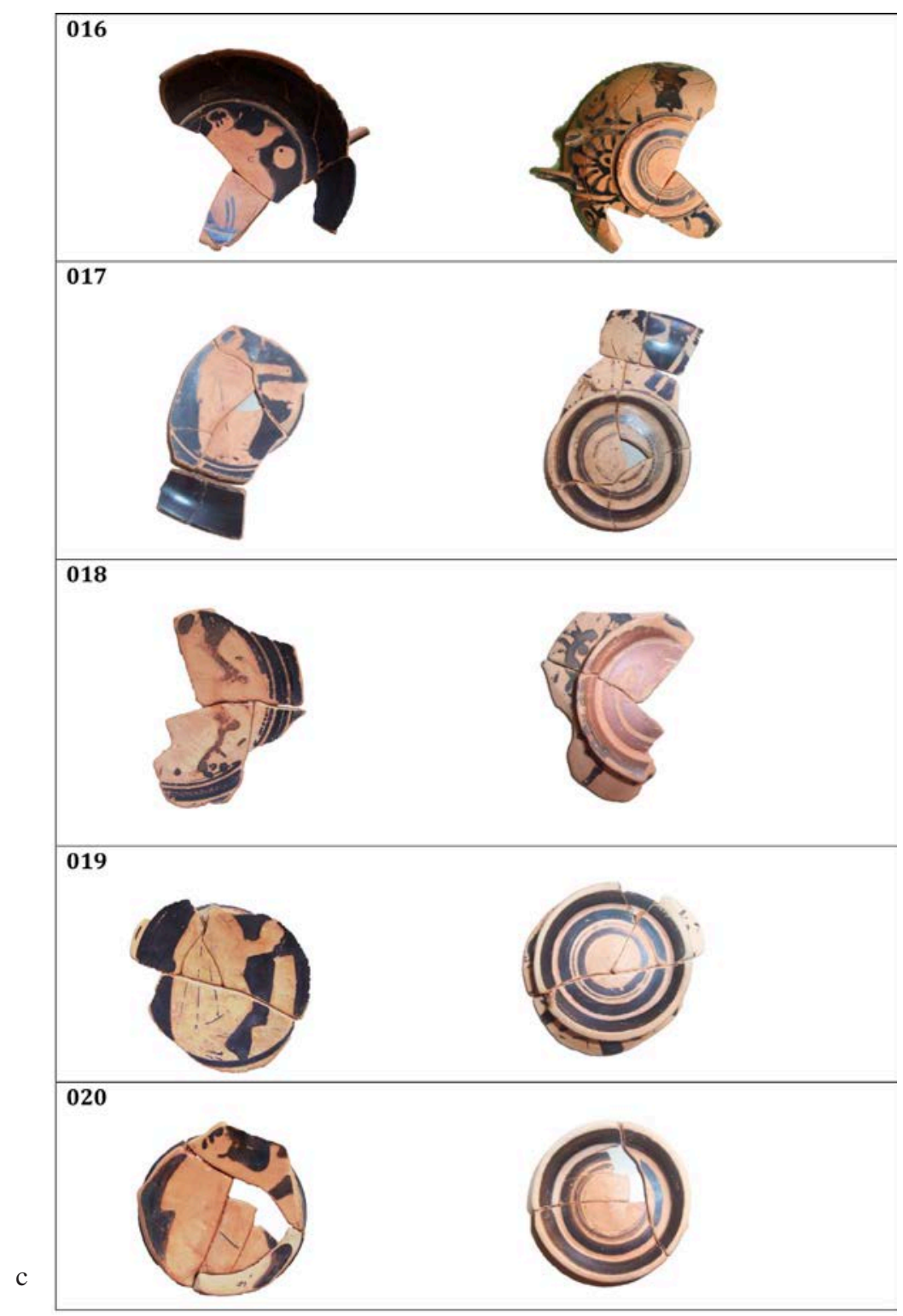

Figura 6. c: Medallones con joven vestido con himatión.

¿039?). Como en el caso de los jóvenes en himatión, estos sostienen en una mano una caja $(005,029)$, una fíala (032), un aribalo (034); la otra mano, la izquierda, sostiene un estrigilo (005, 029,032, 035), sugiriendo que se trata de un atleta. El lugar está caracterizado por un pilar (034) o un altar (039) que puede cerrar también la escena por la izquierda, pero el marco, siempre presente, puede estar también indicado por una roca $(029,040)$ o una media voluta (005, 032, 036). Los atributos o accesorios son el ritón (024), o un disco con una cruz y cuatro puntos inscritos (038).

\subsubsection{Eros: 001, 002, 031, ¿003? (Fig. 7)}

Eros en un medallón, en ese período cronológico, está atestiguado con mayor frecuencia en copas de pie alto $\left(A R V^{2}: 1522-1525\right)$. Tres individuos llevan esta decoración $(001,002,031)$ y el vaso 003 es objeto de debate.

En los dos primeros Eros es tratado de manera similar, dirigiéndose hacia la derecha, volando en uno (001) y caminando en el otro (002), brazos hacia adelante, sosteniendo en la mano derecha un tejido delimitado por puntos (001) o una caja (002). En el 


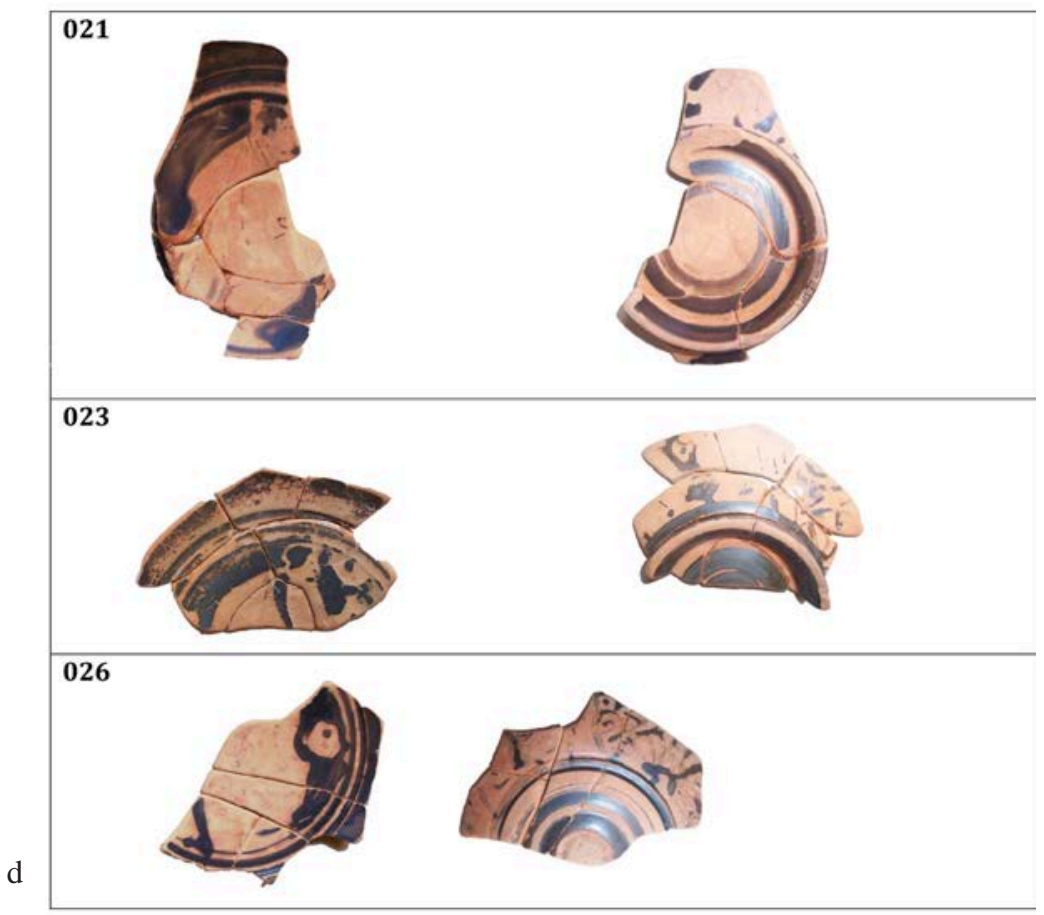

Figura 6. d: Medallones con joven vestido con himatión.

exterior, dos jóvenes en himatión están cara a cara. Cabe señalar que en ambos casos el pelo no se trata como una mancha negra compacta, sino en negro diluido, con mechones en el primer caso.

El caso del Eros del vaso 031 es un poco diferente, con un cuerpo tratado como el de los otros jóvenes desnudos estudiados anteriormente, los brazos hacia delante (mano izquierda sosteniendo una caja) encima de un altar, pero con alas. En el exterior, dos jóvenes en himatión están cara a cara.

La copa 003 lleva en el medallón un personaje alado, de perfil hacia la derecha, por encima de dos volutas. Sus rasgos son aquellos de los jóvenes desnudos; las piernas dobladas, los brazos tendidos hacia adelante. A ambos lados, dos ritá. El dibujo de las manos sorprende: podemos ver un dibujo particularmente burdo o garras, todo también mal dibujado. Eros o híbrido, el debate sigue abierto, especialmente en ausencia de cualquier comparación válida. Exterior barnizado en negro.

\subsection{4. ¿Sátiro: 037? (Fig. 8)}

El vaso 037 suscita también debate. El tratamiento del cuerpo pintado en el medallón es muy parecido al de los jóvenes desnudos, aunque en este caso la superficie erosionada hace muy difícil cualquier lec- tura. El personaje corre hacia la derecha, en dirección de un altar, llevando en su mano izquierda lo que parece ser una caja. Brazo derecho hacia atrás. La presencia de una cola orienta hacia la identificación con un sátiro, pero ningún otro atributo es legible. La cola situada alta en el arco de la espalda no puede ser un obstáculo para esta identificación; esta misma disposición se encuentra por ejemplo en vasos del Pintor de Jena ( $A R V^{2}$ : 1511, 6; Paul-Zinserling 1994: pl 2,1). En el exterior, en ambas caras, dos jóvenes en himatión enfrentados.

\subsection{5. ¿Mujer vestida: 064? (Fig. 9)}

De esta copa subsiste un fragmento de medallón (ancho $4: 4 \mathrm{~cm}$ ) con una cabeza inclinada hacia la izquierda y un cuerpo de frente, vestido. Distinta de las piezas anteriores, con su cabello en negro diluido, su ojo tratado con un triángulo y una ceja marcada es parecida a obras del Pintor de Jena.

2.3.6. Cabeza femenina de perfil: 025, 043, 044, 045, 046, 047, 048, 051, 052, 062 (Fig. $10 a-b$ )

Con once piezas, y la decoración a menudo borrada, este conjunto es particularmente homogéneo. 


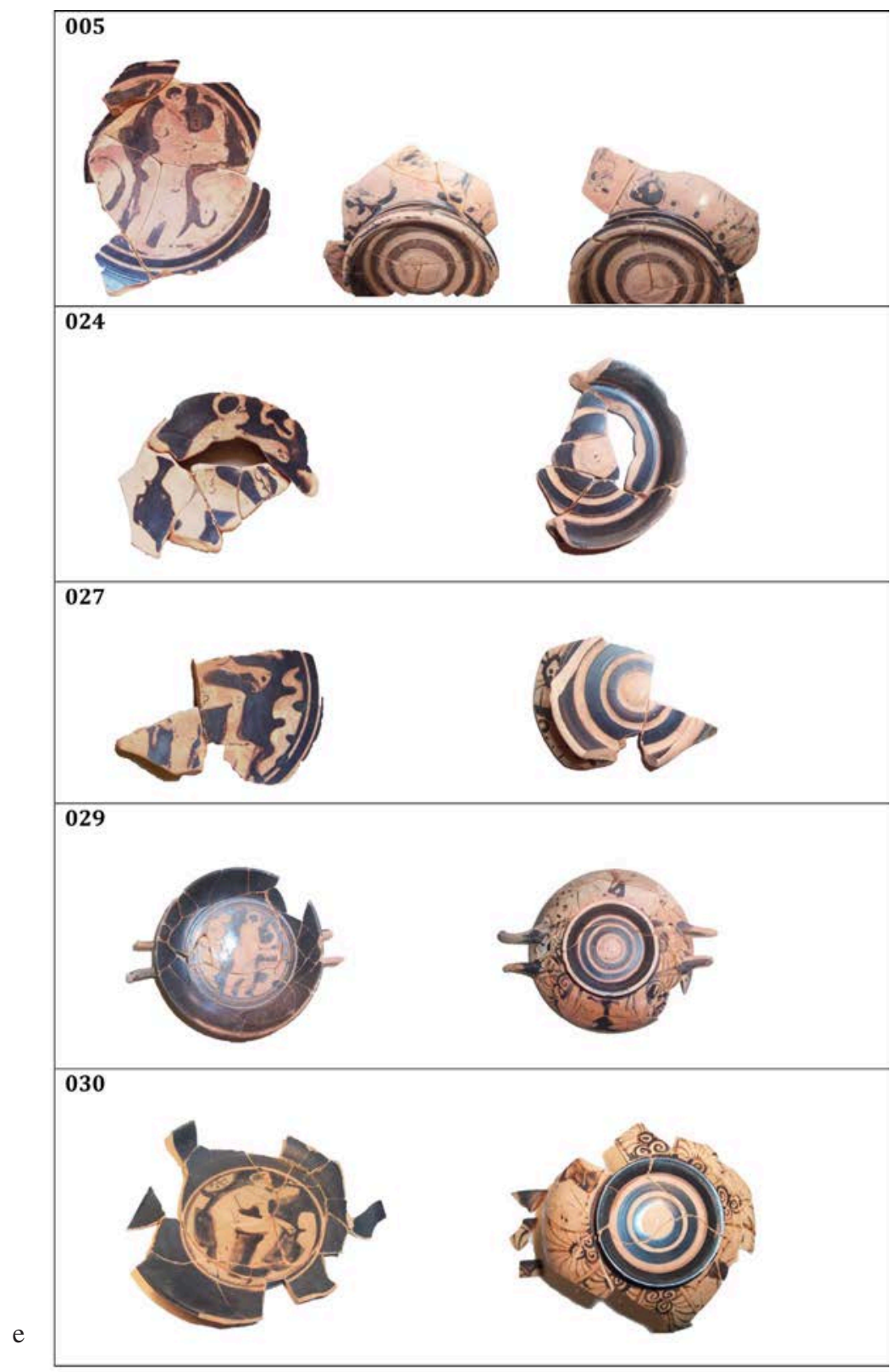

Figura 6. e: Medallones con joven desnudo.

Las cabezas, que ocupan todo el medallón, están de perfil hacia la derecha a excepción de dos piezas (043, 046). El pelo está siempre cubierto por un sakkós de contorno redondeado que se adapta rigurosamente al círculo del medallón, a veces limitado por una línea de puntos (046), o un sakkós de contorno acanalado y delimitado por rosetas de puntos (045), del que escapan a veces mechones sobre la frente (048) o en la oreja $(047,048,051)$. La ceja a menudo se marca con un trazo grueso.

\subsubsection{Otros: ciervo: 004, grifo: 028, 081, esfinge: 065 (Fig. 11)}

En algunos casos el medallón está decorado con un animal o un híbrido. En el vaso 004, el cuerpo de un animal, de perfil hacia la derecha, lleva una línea de puntos sobre el dorso; exteriores con un personaje en himatión. El grifo está presente en dos casos (028, 081), de perfil hacia la derecha; destacamos el primer caso en el que la decoración pintada se realizó 


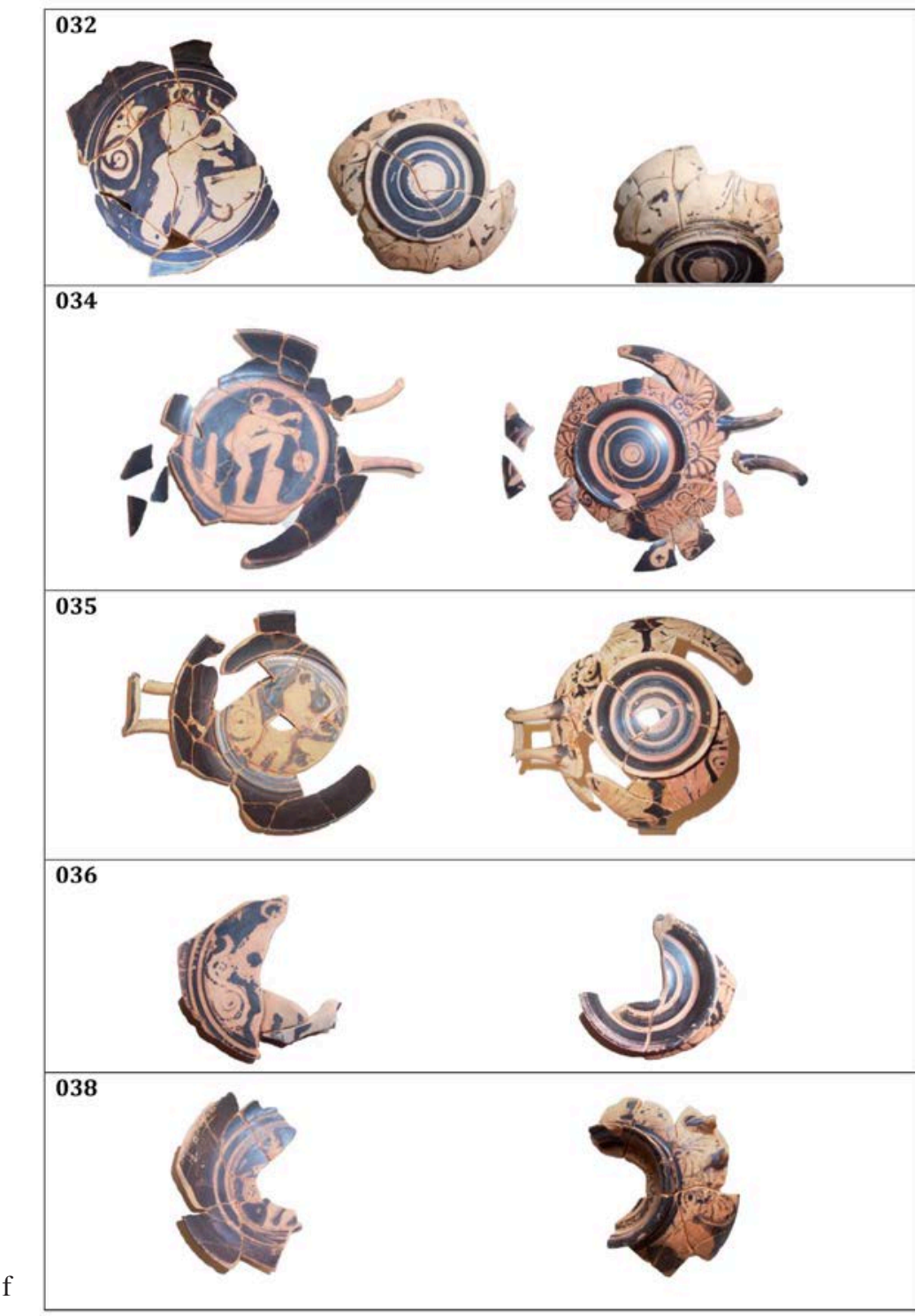

Figura 6. f: Medallones con joven desnudo.

sobre un vaso ya ornamentado con estrías impresas. El fragmento de medallón 065 tiene pintado parte del cuerpo con arranque de ala de una esfinge sentada de perfil a la derecha.

\subsubsection{Exteriores: 084, 075 (Fig. 10b)}

La copa 084 ilustra bien el caso de las caras exteriores, donde se oponen una cabeza femenina y un joven en himatión. La cabeza es tratada como en los medallones, con un sakkos de contorno redondeado del que se escapan mechones de pelo que cubren la oreja; el ojo en triángulo bajo la línea de la ceja. La misma composición se puede encontrar en la copa 075, con a la izquierda una cabeza femenina de perfil hacia la derecha, y a su derecha un disco con puntos (¿tímpano?).

\subsubsection{Personaje no identificable: 033, 041, 069 (Fig. 12)}

Quedan algunos casos de difícil lectura. 033 muestra cierta similitud con el vaso 001, pero Eros no puede vestir una prenda como la que aquí dibujan 


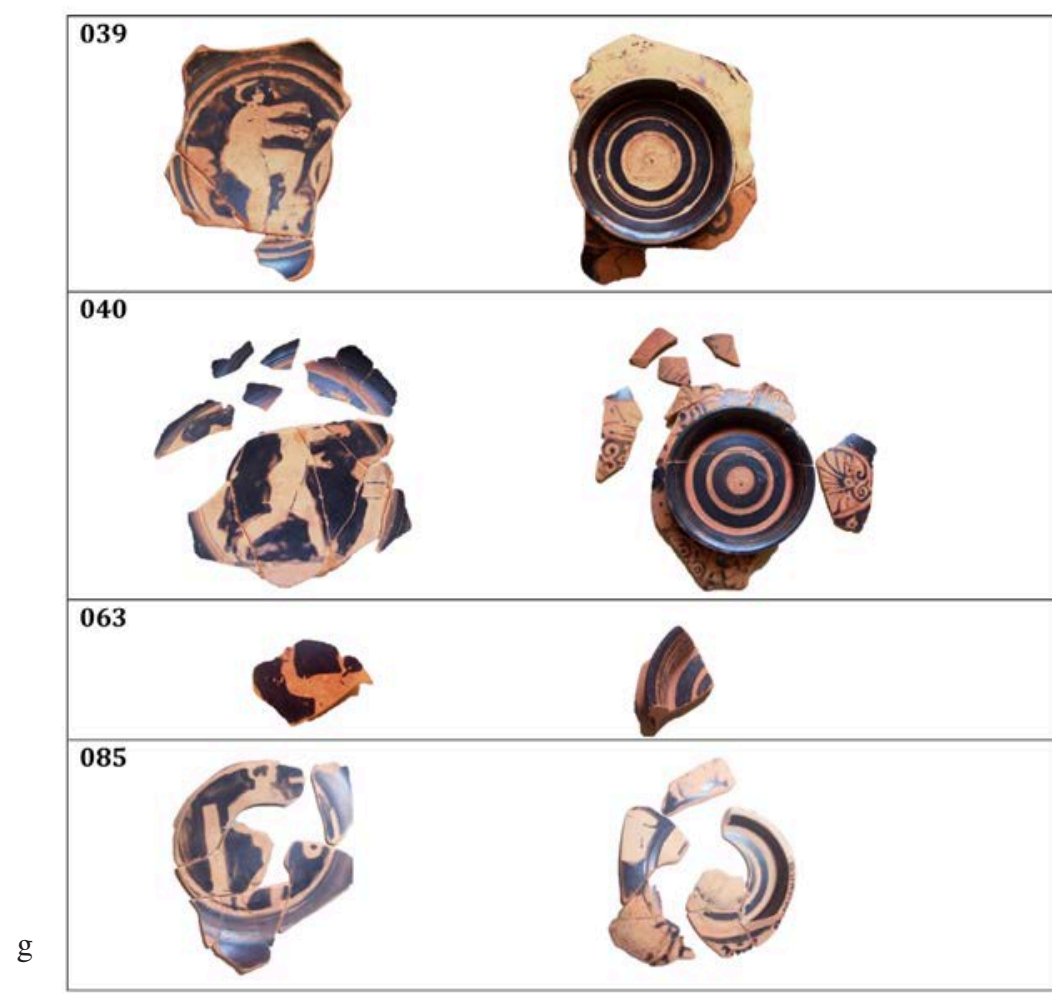

Figura 6. g: Medallones con joven desnudo.

unas líneas verticales. El caso de la copa 041 es particularmente difícil de leer: se puede ver una cabeza de perfil hacia la derecha con un sakkós con rosetas de puntos en la parte posterior, pero el significado de la línea ondulada vertical y el círculo negro arriba no ofrecen una lectura segura. El 069 parece coincidir con la parte derecha de un medallón; reconocer aquí las piernas de una figura sentada es una hipótesis que sigue siendo difícil de defender, por falta de espacio para que haya un torso y una cabeza.

Estas 57 copas de pie bajo presentan innegables puntos en común: la forma, el tamaño, la ornamentación, el tratamiento de los exteriores, la elección de la decoración de los medallones. Esencialmente son los rasgos que han permitido a Beazley atribuir tales piezas al Grupo de Viena 116 (ARV : 1526-1527), una formulación adecuada cuando se distingue, precisamente en este grupo, algunos ejemplos con rasgos comunes bien explícitos. Por un lado la distinción entre medallones con joven en himatión, joven desnudo o cabeza de mujer está presente en $A R V^{2}$. Varios yacimientos ibéricos han venido a enriquecer las series conocidas por el profesor de Oxford, notablemente el pecio de El Sec (Arribas et alii 1987) en la Bahía de Palma de Mallorca, donde se encuentran estos tres principales tipos de decoración, aunque existen matices.
En Zacatín también hay piezas de la misma forma y el mismo estilo, con otras escenas: tal es el caso de Eros, con un ejemplo cercano en Trieste (BA 10334); el grifo se atestigua en una tumba de la necrópolis de Pozo Moro (Chinchilla, Albacete), o la Esfinge, en un fragmento de Ensérune ( $A R V^{2}$ : 1527,2; CVA Coll. Mouret, pl. 8,4). El ciervo que se puede reconocer en la copa 004 está presente con más frecuencia en askoi (véase, por ejemplo, Oxford V 540 = BA 6020).

Estos pocos ejemplos de conexiones entre piezas de Zacatín y otras colecciones y otros lugares confirman la pertenencia al mismo grupo del Pintor de Viena 116. Gracias al número de ejemplares/piezas conservado es posible (en el siguiente capítulo) proponer una reflexión sobre las modalidades de trabajo en este taller. Entre las copas de esta forma, solo una (064) puede ser asignada a otro grupo, al del Pintor de Jena.

2.4. CopAs- escifor: 066, 073, 074, 076, 078, 080, 082 (FIG. 13 a-b)

Dos variantes de esta forma están presentes en este depósito. La primera (066) tiene una pared delgada, un labio poco marcado, un diámetro de $20 \mathrm{~cm}$, y la 


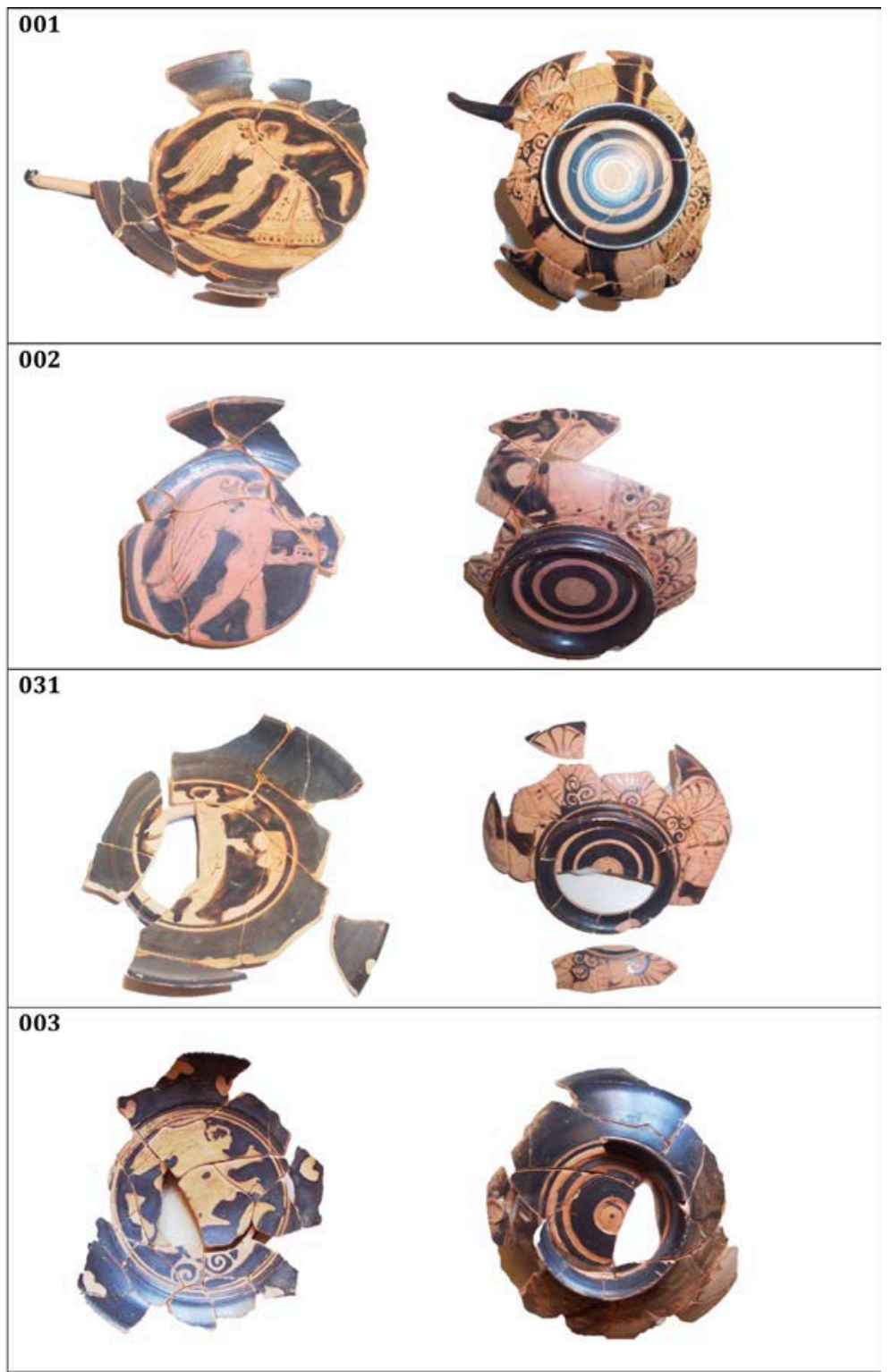

Figura 7. Eros.

decoración cubre toda la altura del cuerpo y del labio. A: muy borrado; a la izquierda, de perfil hacia la derecha, un sátiro (¿o Dionisios?), llevando un tirso y, en frente, un brazo de un personaje dirigido hacia la izquierda con un tímpano; en el labio interno, ramas con pintura superpuesta blanca (borradas) con hojas de hiedra reservadas.

El segundo grupo de copas-escifoi está más atestiguado (6 ejemplares) y se caracteriza por una ranura exterior fuertemente marcada, un diámetro de borde entre 12 y $17 \mathrm{~cm}$; la ornamentación bajo las asas consiste o bien en una palmeta enmarcada por palmetas (073), o bien en volutas $(076,078,082)$; en un caso (076), el labio interior está decorado con hojas en pintura superpuesta. Una decoración incisa y estampillada en el fondo interno del vaso está atestiguada en dos casos: palmetas radiales rodeadas por un círculo de punzones en cruz (076), y palmetas enlazadas rodeadas por un círculo de puntos (080).

El mismo esquema iconográfico se encuentra en los exteriores: dos personajes cara a cara $(074,076$, 080, 082), pero en dos casos es visible en el fragmento un personaje de perfil a derecha (073) o un pie (078). Todas estas características son las que caracterizan 


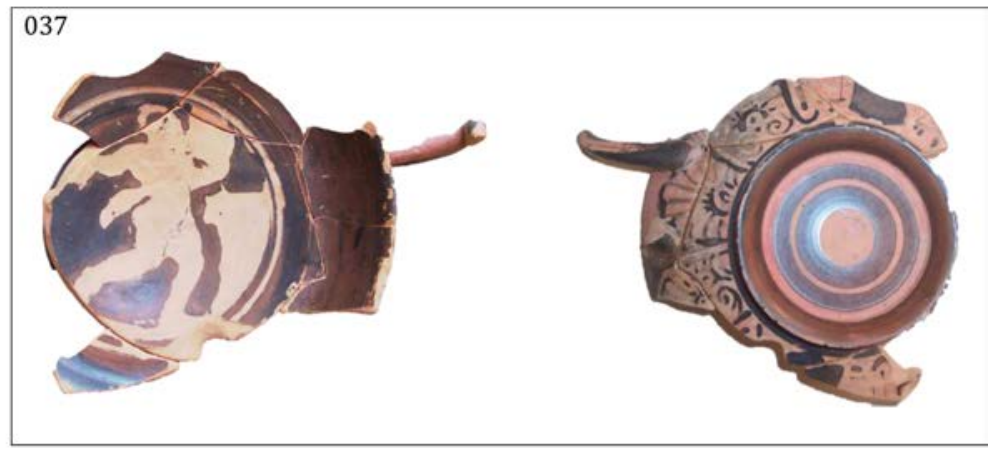

Figura 8. Sátiro.

las copas- escifoi del Pintor Q o de su grupo $\left(A R V^{2}\right.$ : 1518-1521).

2.5. EsCifo “A”: DE TIPO “SAint-VALEnTÍN": 061, DEL "Grupo FB": 070, 071, 072, 079, 094 (FIG. 14)

A esta misma forma pertenecen dos conjuntos, en primer lugar un escifo de tipo "Saint-Valentin" (061) y cinco atribuibles al Grupo del Pintor de FB.

El escifo de "Saint-Valentin" encontrado en Zacatín se caracteriza por su forma compacta, su baja altura de $6,9 \mathrm{~cm}$ (diámetro de borde: $9 \mathrm{~cm}$, diámetro de pie: $7 \mathrm{~cm}$ ). Bajo lengüetas verticales, la decoración está constituida de una banda de hojas opuestas que alterna motivos reservados con barnizados. Este vaso es una de las pocas piezas sometidas al fuego.

Los otros cinco escifoi tienen como primera característica un perfil convexo-cóncavo muy pronunciado (diámetro de pie entre 4 y $6 \mathrm{~cm}$ ). En tres de ellos, solo se ha conservado la parte inferior del cuerpo o el pie; la ornamentación consiste en palmetas verticales (070, 071, 072). En la cara A del escifo 094, dos personajes en himatión afrontados (faltan las cabezas) y entre los dos se superpone un círculo limitado de puntos, un disco reservado y un aribalo. La cabeza conservada de un joven con himatión de perfil hacia la izquierda (079) se caracteriza por una prominente nariz, una boca sin detalle y un himatión que llega hasta la barbilla. Estos rasgos nos permiten situarnos cerca del Pintor de la tumba 248A Spina (Sabattini 2000: 60-61 y 64), una de las personalidades del Grupo FB definido por Beazley (ARV : 1490-1492).

\subsection{Askos: 059 (FIG. 15)}

En el estilo de figuras rojas, el único vaso cerrado es un ascos de colador (059), de $9 \mathrm{~cm}$ de ancho. La decoración consiste, en una cara, en un animal cuadrúpedo (perro) corriendo y en la otra, una liebre. Frente al perro, una voluta. La cazoleta perforada se decora con un filete negro.

\subsection{ConClusión}

A la vista del repertorio de formas producidas en El Cerámico de Atenas, el depósito de Zacatín es muy

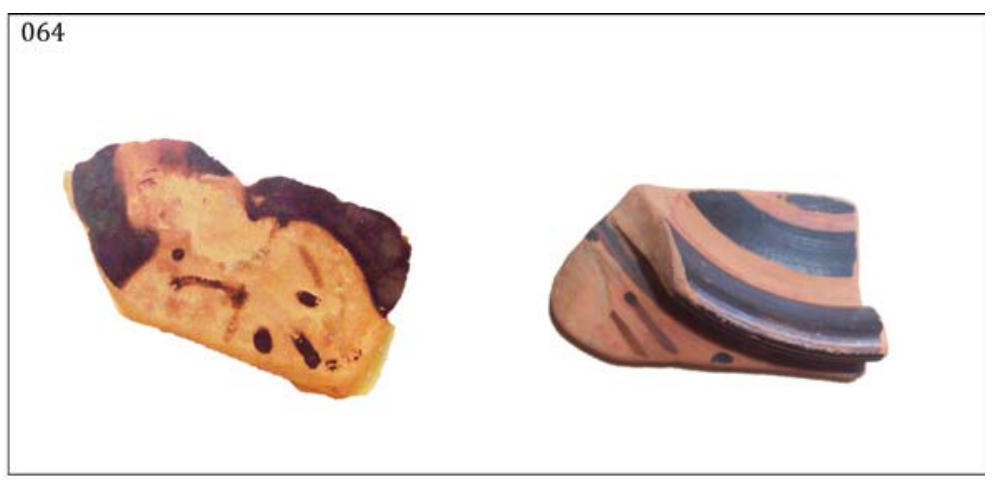

Figura 9. Mujer vestida. 


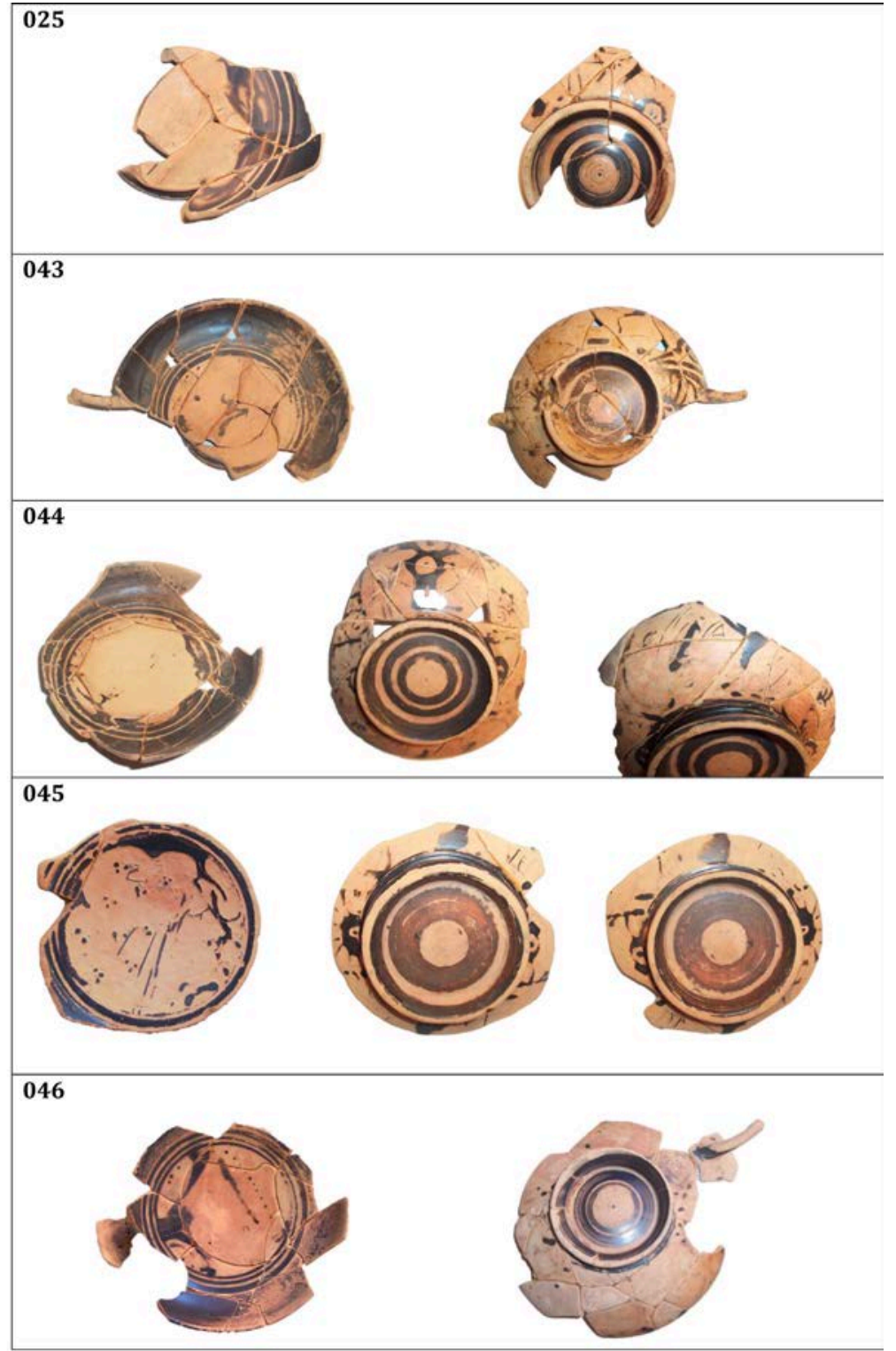

Figura 10. a: Cabeza femenina de perfil.

particular. El mismo depósito es especial comparado con lo documentado en los yacimientos (poblados y necrópolis) de Andalucía, donde junto a los vasos para beber (incluyendo copas de pie bajo y escifoi) se cuenta con numerosas cráteras (Rouillard 1991: 181-185). Aquí, en Granada, dentro del repertorio de la primera mitad del siglo IV a. C. se han privilegiado en este depósito los vasos para beber. La copa de pie bajo es la más abundante, probablemente debido a su comodidad de transporte y sobre todo de acondicionamiento; estas copas son fáciles de superponer y apilar, más que las copas de pie alto, que, sin embargo, están presentes. La presencia de estas últimas copas es excepcional en esta zona (Rouillard 1991: 166-167) e incluso en todo el sur de la Península con algunas excepciones cercanas (en particular, Casa del Monte, Valdeganga, Albacete, en Trías 1967-1968: 431-432, pl. CLXXXIX 9-10); sólo están documentadas en la Península Ibérica en Ampurias (Miró 2006: 138).

Los vasos áticos de figuras rojas de Zacatín son un buen indicador de las producciones del siglo IV a. C. cuando ciertos talleres producen en masa series de piezas muy repetitivas. Lo que el comanditario ha elegido, y/o lo que el comerciante ha proporcionado 


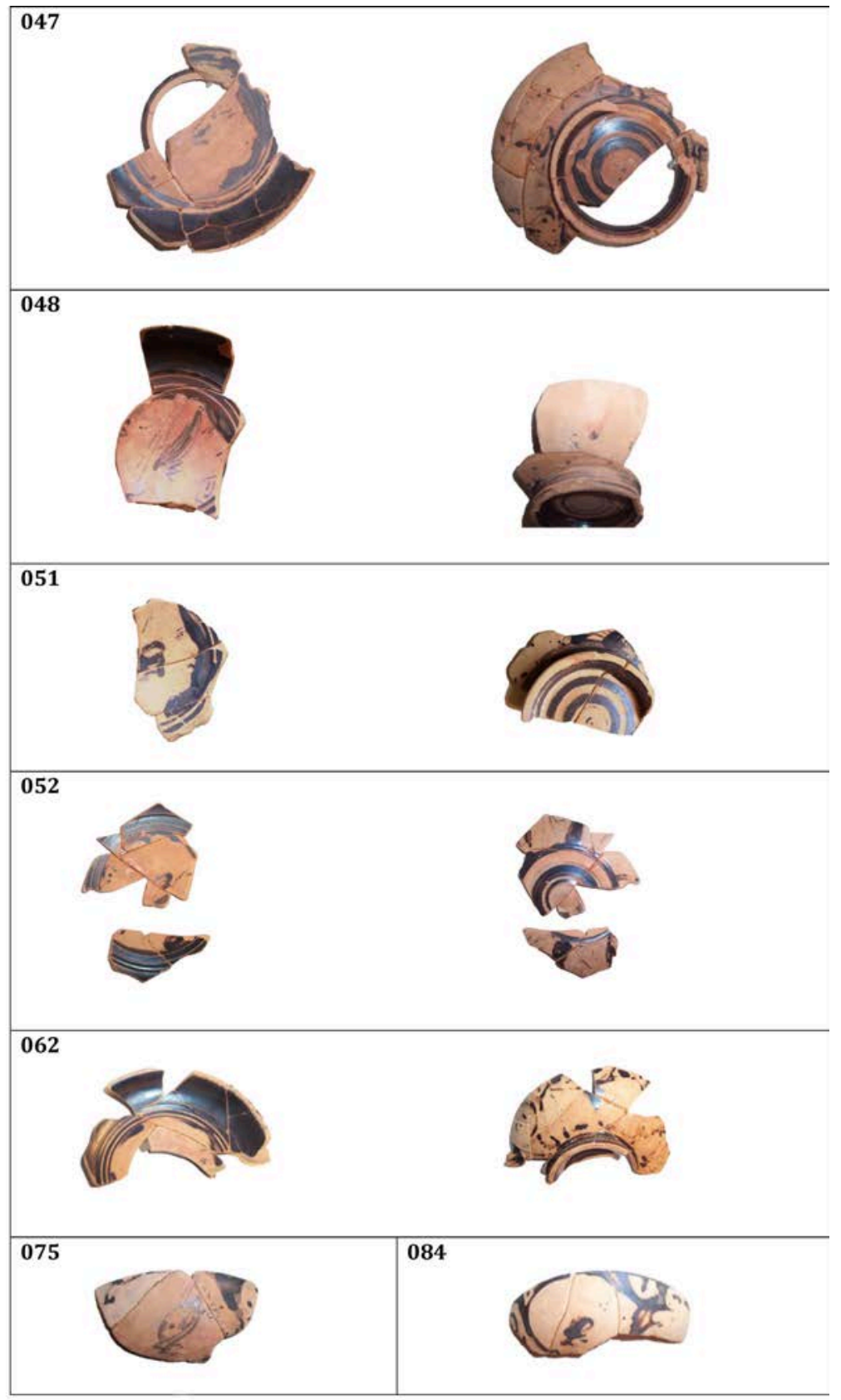

Figura 10. b: Cabeza femenina de perfil.

viene de algunos de los talleres más prolíficos, como el del Pintor de Viena 116, y de un taller muy cercano a éste, el de los pintores que constituyen el Grupo FB. Lo mismo podemos decir para los vasos del Pintor Q y del Pintor de Meleagro halladas en Zacatín, piezas de las más tardías de su producción. Observando el conjunto de este depósito cuya constitución puede ser datada en el segundo cuarto del siglo IV a. C., es perceptible una evidente filiación entre las piezas, lo que permite responder a cuestiones sobre la estructuración de talleres, algunos de los cuales, como el del Pintor de Meleagro, tienen una larga vida útil (Villard 2000: 7; Kathariou 2002).

Las opciones iconográficas participan plenamente en esta homogeneización del material. Los accesorios y atributos, fíala, ritón, halteras, disco, aribalo, estri- 


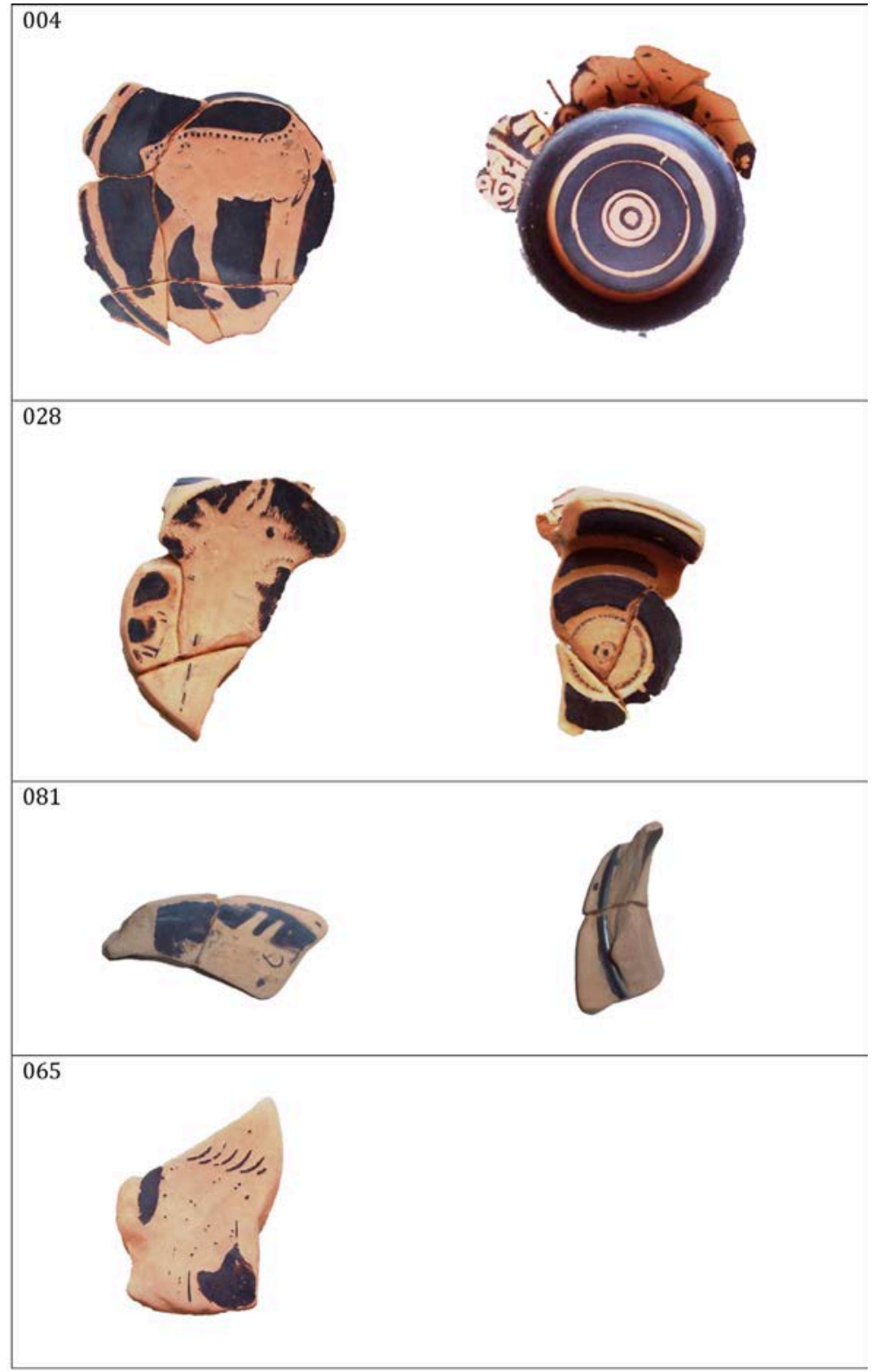

Figura 11. Otros.

gilo están juntos y asociados en una variada mezcla de universos que son los de la ciudad griega, los banquetes, la palestra, los de Eros.

\section{SERIES, ESCUELAS Y TALLERES EN LA CE-} RÁMICA ÁTICA FIGURADA: UN ESTUDIO PRELIMINAR DE LOS VASOS PARA BEBER

La amplitud del contenido del depósito de Zacatín al pie de Illiberris, la antigua Granada, que reúne lo esencial del repertorio de vasos para beber áticos de figuras rojas, permite profundizar en las cuestiones de producción y distribución de esta vajilla en el curso de la primera mitad del siglo IV a. C. En efecto, se cuenta con 6 copas de pie alto, 57 copas de pie bajo con cuerpo de curvatura continua y resalte interno, 2 copas de curvatura continua , 7 copas-escifoi, 6 escifoi y un askos y, lo que es de mayor interés en este conjunto, se detecta por una parte una gran similitud iconográfica y estilística entre todas estas piezas, testimoniando así características propias de un 


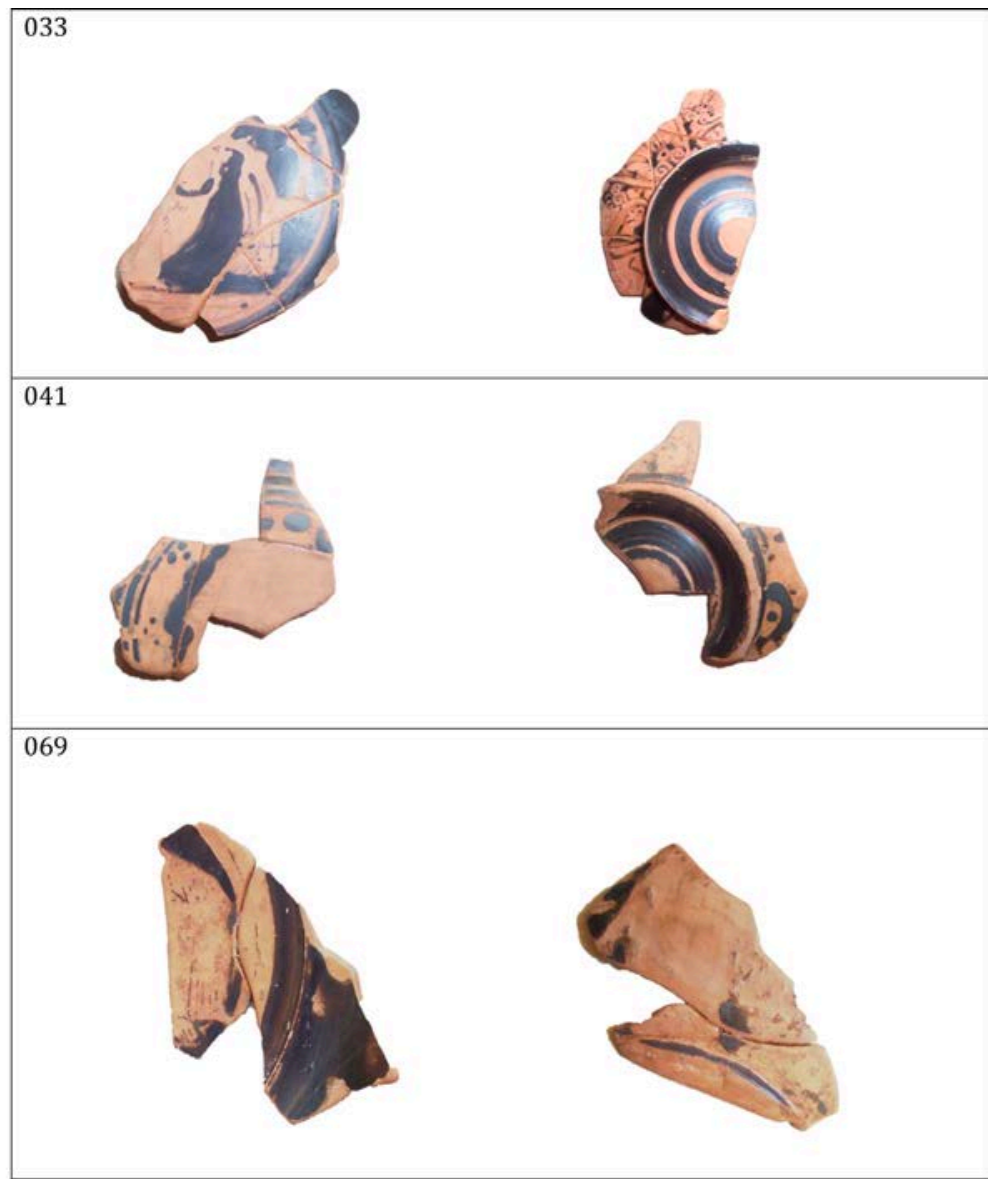

Figura 12. Personaje no identificable.

momento en las producciones áticas y, por otra parte, la existencia en los ejemplares de la misma forma de constantes y de elementos compartidos por diversas piezas, desde la forma a la iconografía, a la decoración y a la ornamentación. Proponemos reconocer así un "lote", que se puede definir como un conjunto de vasos que presentan una misma forma, una elección iconográfica, una organización y una composición casi idénticas, un sistema decorativo que se repite, y una manera de pintar muy similar ${ }^{10}$.

Este estudio -claramente preliminar- tiene por objeto, a partir del caso del Zacatín, profundizar tanto en cuestiones de producciones dentro de un taller o de un "Grupo", en cuestiones de cronología, asuntos ya estudiados (Curti 2001; Sabattini 2000; a menudo

${ }^{10}$ Compararemos entonces los sistemas de Beazley, tal como los define en $A R V^{2}$, p. XLIII, de "clase", que se refiere a la forma, y "grupo", que se refiere al dibujo. También vamos a utilizar esos dos términos en el sentido de Beazley, utilizando la palabra "lote" cuando en cualquiera de los vasos se observen puntos comunes en la forma y el dibujo de los vasos. siguiendo las intuiciones de Beazley y Villard 2000), pero que seguirán suscitando preguntas y debates.

En el conjunto de 57 copas de pie bajo, de curvatura continua y resalte interno, de Zacatín se observan algunos lotes, lo que por supuesto se aplica a otros lugares. Cada sitio ha recibido lo transportado tal cual o en lotes. Algunos lugares reciben muchos lotes, como Zacatín, cuando otros reciben alguno que otro o sólo uno. Podemos analizar tales situaciones con estas copas de pie bajo, incluyendo el análisis del caso Zacatín, y el cargamento del barco de El Sec hundido en la bahía de Palma de Mallorca y datado en el segundo cuarto del siglo IV a. C. (Arribas et alii 1987).

Zacatín cuenta, entre las copas de pie bajo con resalte interno, con un cierto número de lotes: entre las copas con joven en himatión en el medallón, el lote constituido por los vasos 008, 009, 010, 014, el lote de copas 019,020 y el lote de copas 011 y 016 ; entre las copas con el joven desnudo en el medallón, un lote está constituido por las copas 005, 032, 035; 


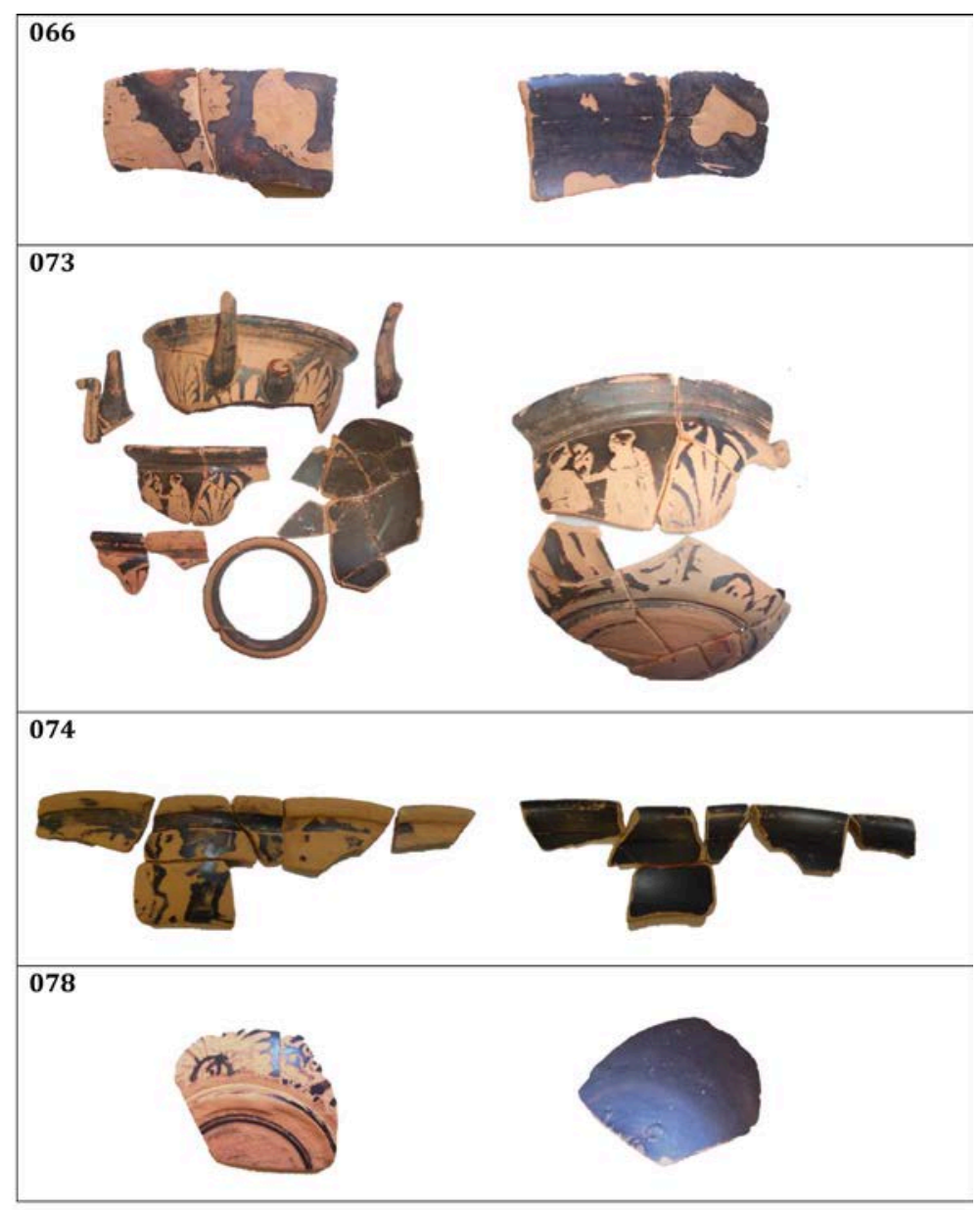

Figura 13. a: Copas-escifoi.

las copas con medallón decorado con un Eros (001, 002) y aquellas decoradas con una cabeza femenina, constituyen otros lotes.

La comparación entre el cargamento de El Sec y el depósito de Zacatín nos arroja luz sobre la composición de los lotes. En el cargamento de El Sec (Trías 1987a) una docena de copas (números 34, 35, 36, 37, 39, 41, 42, 43, 44, 53, 54) tienen un medallón con un joven en himatión, un brazo por encima de un altar con capitel jónico, con una roca o una media voluta a la izquierda, un tipo que no está del todo atestiguado en Zacatín.

Las copas de El Sec 047, 048 y 049 tienen en el medallón un joven en himatión, brazos hacia delante $\mathrm{y}$, debajo del brazo, un disco reservado con una cruz rodeada de puntos; este tipo no está atestiguado en Zacatín, donde sin duda encontramos el mismo esquema, pero el joven tiene un aribalo realizado con un círculo reservado con un punto central (Zacatín 011 y 016).
El caso del joven en himatión, brazos hacia adelante por encima de un luterio en forma de cuenco hemisférico está presente en Zacatín (008, 009, 010), pero no en El Sec.

El joven en himatión puede tener en Zacatín (019, 020), su brazo por encima de un simple pilar, esquema documentado en la tumba 43 de Baza (Presedo 1982: 79, fig. 52, pl. XX); pero en la misma tumba 43 de esta necrópolis estaban también depositadas dos copas con el medallón con un joven en himatión de perfil a la izquierda (Presedo 1982: 86, fig. 53 y 54, pl. XVIII). Así, en el mismo conjunto cerrado de Baza se encuentran reunidas piezas de dos lotes.

Los medallones con joven desnudo de perfil a la derecha, frente a un luterio constituido por un sencillo cuenco de Zacatín $(005,032,035)$ se encuentran en el pecio de El Sec $(52,53,55)$; pero, aunque el esquema es el mismo y el tratamiento del dibujo idéntico, hay una diferencia notable: en el primer lote el joven está sosteniendo un estrigilo, que no es el 


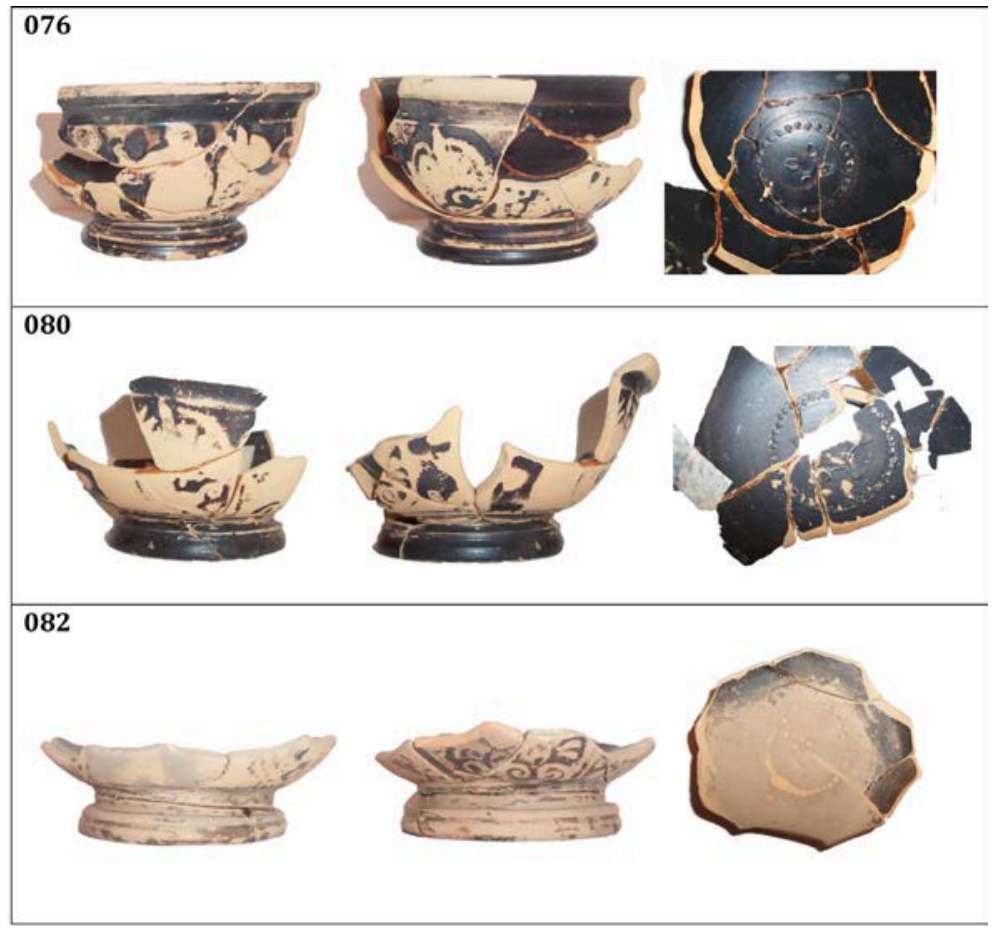

Figura 13. b: Copas-escifoi.

caso en las piezas de El Sec. Destacamos que en los vasos pintados de El Sec nunca aparece el estrigilo.

En el repertorio de copas con joven desnudo de perfil hacia la derecha, hay una similitud perfecta entre la copa de Zacatín 030 y el medallón de Ullastret n. 2864 (Picazo 1977: pl. 16, 2, 3 = BA 31829): en ambos casos nos encontramos con los mismos miembros también mal proporcionados.

Otros lotes están bien atestiguados con copas cuyos medallones están adornados con una cabeza femenina. En Zacatín, en 8 de las 10 copas, la cabeza está de perfil hacia la izquierda, un sakkós redondeado contiene el cabello; este mismo esquema con el mismo tratamiento se encuentra tanto en Olinto (Olynthus V: 149, $\mathrm{n}^{\circ}$ 261, pl. 118) como en Ullastret (Girona) (Picazo, 1977: 56, 144, pl. XXIII, 2 BA = 31809); se observa en El Sec las mismas cabezas de perfil, en diez casos (n. 58 a 67), pero a la izquierda; en dos casos, el mismo tipo de cabeza de perfil a la izquierda se atestigua en Zacatín. En el conjunto de Zacatín, una sola pieza con la cabeza de perfil a la derecha no tiene el sakkós de contorno que se ajusta rigurosamente al círculo del medallón, sino un sakkós de contorno acanalado y delimitado por rosetas de puntos (045). El repertorio de El Sec marca alguna que otra especificidad con las cabezas de Arimaspos de perfil a la derecha (68 y 69), un tipo ausente en Zacatín, pero que se encuentra por ejemplo en El Cigarralejo (Mula, Murcia) (Rouillard 1975: 38-39, pl. XXI-XXIII): uno de nosotros (P.R.) había propuesto reconocer la mano de un pintor, el Pintor del Cigarralejo, que se caracteriza por rasgos faciales más angulares que en las realizaciones del Pintor de Viena 116.

La cabeza de grifo es una decoración menos atestiguada para los medallones de copas de pie bajo, pero el diseño es muy similar de un sitio a otro: Zacatín (028, 061), Pozo Moro (Chinchilla, Albacete) (Alcalá Zamora 2003: 104-106 fig. 4 y 30) o Baza (Granada) (Presedo 1982: 260, 263, 285, fig. 215).

Contamos con tres casos de medallones decorados con un Eros (001, 002, 031), aunque el caso de la pieza 003 está sujeto a discusión, lo que indica que Zacatín recibió un lote de piezas raramente documentadas en otra parte; citamos un ejemplar de Trieste S 465 (10334 BA).

En Zacatín las copas de pie bajo están generalmente atestiguadas con varios ejemplares con el mismo tratamiento, y rara vez se encuentran ejemplares únicos. Las piezas de los lotes presentes en Zacatín se encuentran en otros sitios de la Península; pero cada uno de estos lugares tiene piezas de uno o dos lotes. El cargamento de El Sec no contiene los mismos lotes que los que llegan a Granada. Los lotes presentes en 


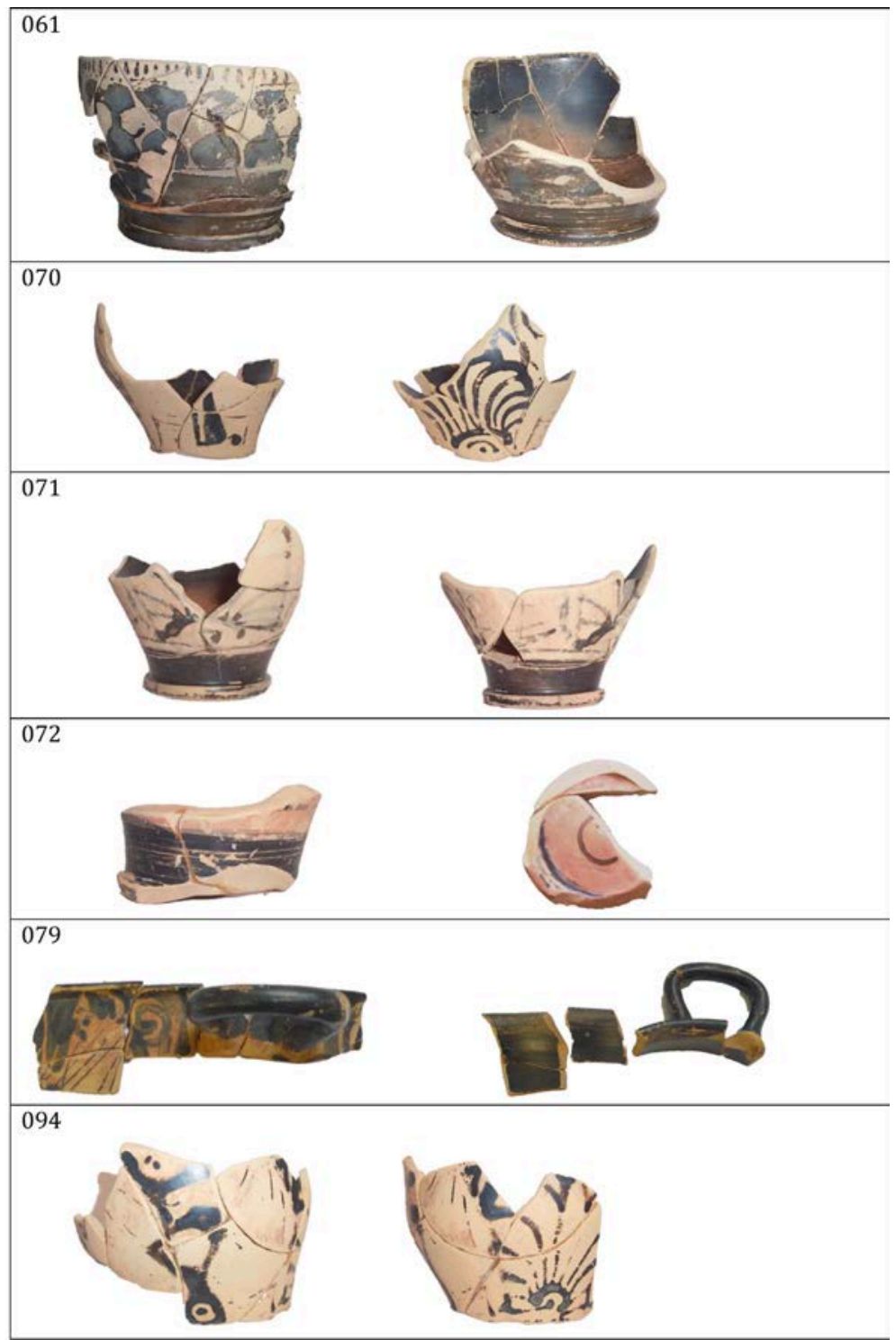

Figura 14. Escifoi.

Zacatín no se encuentran jamás asociados en otro sitio; de hecho una selección muy amplia llegó a Zacatín.

Esta investigación preliminar nos conduce así a formular la hipótesis de la existencia de producciones de pequeños lotes, diseminados, que se encuentran aislados o asociados en un sitio y cuyas piezas pueden ser asociadas en una tumba, como es el caso en la tumba 43 de Baza (Presedo 1982: 66-86).

El análisis de cinco copas de pie alto 042, 055, 056, 057, 058 (la copa 083 está demasiado fragmentada para suscitar cualquier reflexión) ha permitido mostrar la existencia de un lote tanto por la iconografía como por el tratamiento de los personajes, la ornamentación y la forma de estos vasos, parecidos unos a otros (Rouillard y De la Torre 2014 y supra cap. 2), y una atribución al Pintor de Meleagro. Uno de los caracteres constantes de las copas de pie alto de este Pintor es la presencia en el medallón de uno o dos personajes bien centrados y bien destacados; en este lote de Zacatín, el personaje es único y centrado. Sin duda nos encontramos con ciertos rasgos de otros pintores: así, la ornamentación de las caras exteriores es muy cercana a copas de los Pintores de Jena o Q. Otro ejemplo, con la copa de S465 de Trieste (BA 10334), cuyo medallón está decorado con un Eros, atribuido al Pintor de Viena 116, pero que constituye 


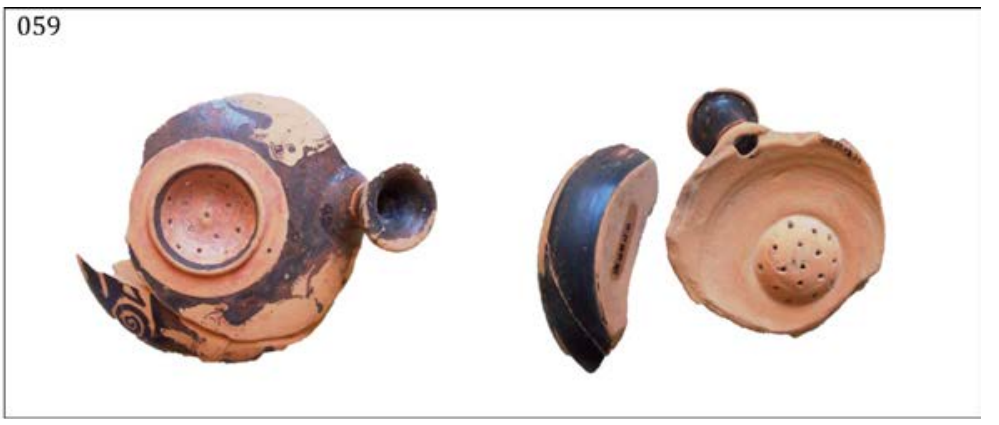

Figura 15. Askos.

un caso muy particular en el repertorio de las obras de este Pintor, en el que el medallón está generalmente congestionado por atributos, accesorios y elementos ornamentales.

De hecho, estas copas de pie alto constituyen un lote muy particular, algunos de cuyos atributos se encuentran en los Pintores de Jena o Q. Por otro lado, el conjunto más importante del depósito de Zacatín lo constituyen la masa de copas del Pintor Viena 116 y algunos vasos del Grupo del Fat Boy. A estos dos conjuntos, se suman copas-escifoi y entre todas estas piezas se observan "des citations" la determinación de un estilo de un momento. Por lo tanto, las cuestiones de la duración y la estructura de los talleres deben ser contempladas en conjunto.

Eros constituye un ejemplo de tema tratado más o menos de la misma manera en estos dos conjuntos y esto vale para los sistemas de ornamentación. Estas filiaciones pueden desarrollarse a lo largo de un cierto tiempo, pero podrían ser compartidas dentro de un gran taller, que cuenta con muchas manos que recurren a esquemas comunes realizados de manera diferente. Esta es probablemente la cuestión central a la que sólo respuestas parciales (pero a veces contradictorias...) pueden ser aportadas.

El análisis de las asociaciones en las tumbas - y el caso de Spina es ejemplar (Massei 1978; Curti 2001: $30)$ - permite identificar al menos dos momentos. Los vasos del Pintor de Meleagro en las necrópolis de Spina se encuentran asociados con vasos del Grupo G, skyphos de tipo "Saint-Valentín”, vasos del Pintor $\mathrm{Q}$ o del Grupo del Fat Boy. Estos tres últimos conjuntos están presentes en Zacatín. Ningún conjunto cerrado reúne vasos del Pintor de Meleagro y los del Pintor Viena 116 para el cual hay consenso para una datación en el segundo cuarto del siglo IV a. C. (Trias

${ }^{11}$ Utilizamos la palabra francesa por no haber encontrado una traducción adecuada en un solo término; nos referimos a «citas estilísticas» o «referencias estilísticas». 1987a: 123 y 1987b: 37 y recientemente Langner 2013: $140-142)^{12}$.

La primera mitad del siglo IV a. C. cuenta con talleres de larga vida, sin duda con muchos artesanos y muchas manos, como se ha señalado, en primer lugar, a partir de cráteras o pelikai, por Talcott y Philippaki (1956: 9-10), Villard (2000), Kathariou (2002) o Langner (2013), o a partir de escifoi (Sabattini 2000). Gracias a estos trabajos, a menudo basados en gran parte en el análisis de las formas, sabemos que el Grupo de Telos está a caballo entre el primer y segundo cuarto de siglo IV a. C. (Langner 2012: 36 , nota 8, 11 y 12), que el Pintor de Filotrano está a caballo entre el segundo y tercer cuarto del siglo IV a. C. (Langner 2012: 36, notas 9 y 13) y el Pintor del Tirso Negro, cuyas obras están asociadas, sobre todo en Andalucía, con copas del Pintor de Viena 116 (Rouillard 1991: 184; 2008: 84-85), también cabalga entre el segundo y tercer cuarto del siglo IV a. C. (Talcott y Philippaki 1956: 9); sabemos ahora que el Pintor de la Amazona estuvo activo hasta finales del siglo IV a. C. (Eschbach 2014: 105-107). Las modalidades prácticas de funcionamiento de estos talleres a menudo se nos escapan; pero se reconoce la existencia de "piu artigiani" en el taller del Pintor de Meleagro (Curti 2001: 39) que dentro del Grupo FB: "they are a good many hands", como observa Beazley $\left(A R V^{2}\right.$ : 1484), una observación amplificada y luego fuertemente argumentada por Sabattini (2000), o ahora, como hemos mostrado, una producción en lotes del pintor de Viena 116. Otros datos contribuyen a una mejor comprensión de las condiciones

\footnotetext{
${ }^{12}$ Completamos para la Península Ibérica, con tres conjuntos cerrados que cuentan con copas de este pintor: el ustrinum de Baza (Granada), con copas de Viena 116 y copas-escifoi de barniz negro (Presedo 1982: 262-264, fig. 213 -216); la tumba 24 de Senda en Jumilla (Murcia), con copas de Viena 116, escifoi del Grupo FB y el cuenco de borde entrante (García Cano, 1997: 37, 99-102 y 309-312; la tumba 1 de Ceal (Jaén) de septiembre de 1956, con tres copas de Viena 116 y un escifo del Grupo FB (Chapa et alii 1998: 55-56, 192-195, fig. 24, 1-3).
} 
de producción: las copas del Pintor de Viena 116 y algunos vasos del Grupo del Fat Boy comparten el mismo gusto por la decoración sobrecargada hasta el punto de que Beazley ( $A R V^{2}: 1482$ y 1526), sugería ya que un mismo taller reunía a artesanos que producían estos skyphoi y estas copas; otra información fundamental la ha proporcionado el estudio de Norbert Eschbach (Eschbach 2014): que el mismo horno del Cerámico, de finales del siglo IV a. C., fue utilizado para cocer todo a la vez, desde ánforas panatenaicas, a vasos de barniz negro y pelikai de figuras rojas decoradas con cabezas de Amazonas y grifos, y para diferentes clientes.

La constitución de este depósito de Zacatín suscita todavía interrogantes porque no disponemos de la estratigrafía para el material ático. El análisis del material ático sugiere la existencia de dos conjuntos. El depósito pudo ser efectuado en dos momentos o, más bien, en un solo momento con piezas ya utilizadas por los habitantes de Iliberri (incluyendo las copas de pie alto) a las que se asocian una gran cantidad de vasos (copas de pie bajo del Pintor de Viena 116 y escifoi del Grupo FB) del segundo cuarto del siglo IV a. C. El material de barniz negro, ático también, sugiere la misma idea con un pequeño conjunto de piezas del final del siglo v a. C. (con copas de tipo "Cástulo") y un conjunto muy abundante de cuencos con borde entrante del segundo cuarto del IV a. C. (Adroher et alii 2016). Cualquiera que sea la historia de este depósito, los vasos griegos constituyen un buen comienzo para suscitar debates sobre la vida de los talleres atenienses de la primera mitad del siglo IV a. C., con sus filiaciones, sus "citations" y sus pequeños lotes expedidos desde un extremo al otro del Mediterráneo y que nosotros encontramos reagrupados de manera diferente en función de las vicisitudes de los tráficos.

Nota: Todas las fotografías incluidas en las figuras son de los autores del artículo.

\section{BIBLIOGRAFÍA}

Adroher Auroux, A. M. 2008: "La Bastetania arqueológica. Estado de la cuestión”, A. M. Adroher y J. Blánquez (eds.), ler Congreso Internacional de Arqueología Ibérica Bastetana, Varia, 9, 1, Madrid, 211-246.

Adroher Auroux, A. M. 2014a: "Metodología de registro: el sistema SIRA, una propedéutica", Oikos 2, 177-185.

Adroher Auroux, A. M. 2014b: "Propuesta de gestión de cerámica en contextos arqueológicos: el sistema de información de registro arqueológico (S.I.R.A.)", R. Morais, A. Fernández y M. J. Sousa (eds.), As produções cerâmicas da imitaçao na Hispania, 1, Monografias ex officina Hispana 2, Porto, 611-620.

Adroher, A. M. y López, A. (eds.) 2001: Excavaciones arqueológicas en el Albaicín I. El Callejón del Gallo, Granada.
Adroher A. M., Sánchez Moreno, A. y De la Torre, I. 2015: "Cuantificación en cerámica ¿ejercicio especulativo o ejercicio hipotético? Las cerámicas ibéricas y púnicas en la Iliberri del siglo IV a. C. procedentes del depósito de la calle Zacatín (Granada)", Archivo Español de Arqueología 88, 39-65.

Adroher A. M., Sánchez Moreno, A. y De la Torre, I. 2016: "Cerámica ática de barniz negro de Iliberri (Granada. España). Análisis crono-estadístico de un contexto cerrado", Portugalia, Nova Série 37, Porto, 5-38.

Agora XII = véase Sparkes y Talcott 1970.

Alcalá-Zamora, L. 2003: La necrópolis ibérica de Pozo Moro. Real Academia de la Historia, Bibliotheca Archaeologica Hispana, 23, Madrid.

Arribas Palau, A. 1967: "La necrópolis bastitana del Mirador de Rolando (Granada)", Pyrenae 3, 67-105.

Arribas, A., Trías, G., Cerdá, D. y de Hoz, J. 1987: El barco de El Sec (Costa de Calvià, Mallorca). Estudio de los materiales, Mallorca.

$\mathrm{ARV}^{2}=$ Véase Beazley 1968.

Beazley, J. D. 1948: "La cerámica ática del Cabezo del Tío Pío en Archena (Murcia)", Cuadernos de Historia Primitiva III, 43-50.

Beazley, J. D. 1968: Attic Red-Figure Vase-Painters, Oxford, $2^{\mathrm{a}}$ ed. (citado $\left.\mathrm{ARV}^{2}\right)$.

Bloesch, H. 1940: Formen Attischer Schalen von Exekias bis zum Ende des Strengen Stils, Bern.

Chapa, T., Pereira, J., Madrigal, A. y Mayoral, V. 1998: La necrópolis Ibérica de los Castellones de Céal (Hinojares, Jaén), Sevilla.

Curti, F. 2001: La bottega del Pittore di Meleagro, Suppl. alla Rivista di Archeologia 25, Roma.

De 1a Torre, I. 2008: "Avance del estudio de materiales del depósito del Zacatín (Granada)aproximación cuantitativa y tipológica de la cerámica del depósito", A. M. Adroher y J. Blánquez (eds.), 1er Congreso Internacional de Arqueología Ibérica Bastetana, Varia, 9, 2, Madrid, 107-115.

Eschbach, N. 2014: "Athenian Vases for whom ? A new workshop of the late 4th century in the Athenian Kerameikos", Metis N. S. 12, 99-118.

García Cano, J. M. 1997: Las necrópolis ibéricas de Coimbra del Barranco Ancho (Jumilla, Murcia). I. Las excavaciones $y$ estudio analítico de materiales, Murcia.

Kathariou, Kl. 2002: L'atelier du peintre de Méléagre et son époque, Remarques sur la céramique attique du Ier quart du IVe s., Thessaloniki.

Kossatz-Deissmann, A. 1986: "Observazioni sulle nascite di Afrodite ed Atenea nell' arte greca", Actas del Coloquio sobre el Puteal de la Moncloa. Estudios de Iconografía II, Madrid, 125-149.

Langner, M. 2012: "Kam es auf die Bilder an ? Handelskontakte, Verwendungskontexte und lokale Imitationen spätrotfiguriger Vasenbilder aus Athen", Corpus Vasorum Antiquorum Beihefte 6, München, 35-50.

Langner, M. 2013: "Grundlagen der Chronologie spätrotfiguriger Vasen aus Athen”, Bulletin Antieke Beschaving 88, 127-130.

Lozano, J. M., Gámez-Leyva, M. ${ }^{a}$ L., Ruiz, G. y Hódar, M. 2008: "Denominación, edad y funcionalidad del depósito de agua hallado en las calles Álamo del Marqués y San José (Albaicín, Granada)", A. M. Adroher y J. Blánquez (eds.), I Congreso Internacional de Arqueología Ibérica Bastetana, Varia, 9, 2, Madrid, 117-130.

Massei, L. 1978: Gli askoi a figure rosse nei corredi funerari delle necropoli di Spina, Milano. 
Miró i Alaix, M. T. 2006: La Ceràmica àtica de figures roges de la ciutat grega d'Emporion, Monografies emporitanes, 14, Barcelona.

Mora, G. 1998: Historias de Mármol: la arqueología clásica española en el siglo XVIII, Anejos de Archivo Español de Arqueología XVIII, Madrid.

Orfila, M. 2011: Florentia Iliberritana. La ciudad de Granada en época romana, Granada.

Pachón, J. A. 1997-1999: “El depósito de cerámicas griegas de la calle Zacatín", Boletín de Real Academia de Bellas Artes de Granada 6-7, 189-191.

Paul-Zinserling, V. 1994: Der Jena-Maler und sein Kreis. Zur Ikonologie einer attischen Schalenwekstatt un 400 v. chr., Mainz.

Picazo, M. 1977: La cerámica ática de Ullastret, Barcelona.

Presedo Velo, F. 1982: La necrópolis de Baza, Excavaciones Arqueológicas en España, 119, Madrid.

Rambla Torralvo, J. A. y Cisneros García, M. ${ }^{a}$ I. 2000: "Un depósito excepcional de materiales del siglo IV a. C. en Granada", Revista de Arqueología 235, 42-49.

Rambla Torralvo, J. A. y Salado Escaño, J. B. 2002: "Hallazgos de época ibérica y musulmana junto a la Alcaicería de Granada", Anuario Arqueológico de Andalucía 1999, III-1, 175-185.

Rouillard, P. 1975: "Les coupes attiques à figures rouges du IVème siècle en Andalousie", Mélanges de la Casa de Velázquez XI, 21- 49.

Rouillard, P. 1991: Les Grecs et la Péninsule Ibérique du VIIIe au IVe siècle avant Jésus-Christ, Paris.

Rouillard, P. y De la Torre, I. 2014: "Les coupes à tige attiques de Zacatín (Grenade): premières réflexions sur un lot de vases du IVe s. av. J.-C.", Bastetania 2, 1-14. Disponible en http://bastetania.ceab.es/

Sabattini, B. 2000: "Les skyphos du F.B. Group à Spina: apport chronologique de l'étude stylistique et typologique", B. Sabattini (dir.), La céramique attique du IVe siècle en Méditerranée Occidentale, Napoli, 47-65.

Sánchez Moreno, A. 2016: La formación del oppidum de Iliberri y la evolución diacrónica de su territorio, Tesis doctoral, Granada.
Sánchez Moreno, A., Niveau de Villedary, A. M. y Adroher, A. M. 2015: “SSolamente platos? Cerámicas de barniz rojo en el depósito ibérico del Zacatín (Granada)", Saguntum 47, 51-72. https://doi.org/10.7203/sagvntvm.47.5219

Sparkes, B. A. y Talcott, L. 1970: The Athenian Agora. XII. Black and plain pottery of the 6th, 5th and 4th centuries B.C., Princeton-New Jersey (citado Agora XII).

Talcott, L. y Philippaki, B. 1956: Small objcts from the Pnyx: II, Hesperia, Supplement X, Princeton.

Trakatelli, L. 2011: "Representations of animals in hellenistic times: some examples from pottery", M. Jufresa y M. Reig (eds.), Ta Zôia: L'espai a Grècia II: els animals $i$ l'espai. (Documenta; 20), Colloqui Internacional sobre la Concepció de l'Espai a Grècia, 121-136.

Trías, G. 1967-1968: Cerámicas griegas de la Península Ibérica, Valencia.

Trías, G. 1987a: "La cerámica ática de figuras rojas", Arribas, A., Trías, G., Cerdá, D. y de Hoz, J., El barco de El Sec (Costa de Calvià, Mallorca). Estudio de los materiales, Mallorca, 47-176.

Trías, G. 1987b: "El Sec: La cerámica ática de figuras rojas", P. Rouillard et M. C. Villanueva-Puig (dir.), Grecs et Ibères au IVe siècle avant Jésus-Christ, commerce et iconographie, Revue des Etudes Anciennes LXXXIX 3-4, 21-49. https:// doi.org/10.3406/rea.1987.4274

Vílchez, C., De la Torre, I. y Adroher, A. M. (coords.) 2005: Los vidrios griegos en Granada, Granada.

Villard, F. 2000: "La place de 1'Occident dans les exportations attiques à figures rouges au IVe siècle", B. Sabattini (dir.), La céramique attique du IVe siècle en Méditerranée Occidentale, 7-10.

Wiel-Marin, F. 2005: La cerámica attica a figure rosse di Adria, La famiglia Bocchi e l'archeologia, Padova.

Recibido: 21-09-2016

Aceptado: 13-12-2016 